Supporting information for

\title{
Anion recognition by 1,2,3-triazolium receptors: Application of click chemistry in anion recognition
}

\author{
Anjul kumar and Pramod S. Pandey*a \\ Department of Chemistry, Indian Institute of Technology Delhi, Hauz \\ Khas, New Delhi 110016, India. Fax: +91 11 26582037; Tel: +91 11 \\ 26591506 \\ E-mail:pramod@chemistry.iitd.ac.in
}

\section{Synthesis of receptors}

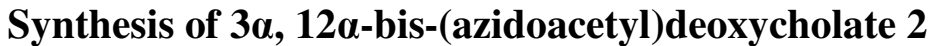

To a solution of 1 ( $1 \mathrm{~g}, 1.54 \mathrm{mmol})$ in $20 \mathrm{ml}$ of DMF, was added sodium azide $(0.6 \mathrm{~g}$, $9.24 \mathrm{mmol}$ ) and solution was stirred at $60{ }^{\circ} \mathrm{C}$ for $12 \mathrm{~h}$. The solution was diluted with 40 $\mathrm{ml}$ of water and extracted with $30 \mathrm{ml}$ of ethyl acetate twice. Organic layer was washed with water and then with brine solution, dried over $\mathrm{Na}_{2} \mathrm{SO}_{4}$ and evaporated under vacuum to give 2 as white solid. Yield: (95\%). Melting point: $79-80{ }^{0} \mathrm{C}$. IR $(\mathrm{KBr}): v_{\max } / \mathrm{cm}^{-1}$ 2108.32, 1753.82; ${ }^{1} \mathrm{H}$ NMR (300 MHz, $\mathrm{CDCl}_{3}$, TMS) $\delta 0.75$ (s, 3H, 18-Me), $0.81(\mathrm{~d}, \mathrm{~J}=$ $6.0 \mathrm{~Hz}, 3 \mathrm{H}, 21-\mathrm{Me}), 0.93$ (s, 3H, 19-Me), 1.01-2.34 (26H, steroidal H), 3.66 (s, 3H, $\left.\mathrm{OCH}_{3}\right), 3.83\left(\mathrm{~s}, 2 \mathrm{H}, \mathrm{CH}_{2} \mathrm{~N}_{3}\right), 3.89\left(\mathrm{~s}, 2 \mathrm{H}, \mathrm{CH}_{2} \mathrm{~N}_{3}\right), 4.82(\mathrm{~m}, 1 \mathrm{H}, 3 \beta-\mathrm{H}), 5.26(\mathrm{~s}, 1 \mathrm{H}, 12 \beta-$ $\mathrm{H}) ;{ }^{13} \mathrm{C}$ NMR (75 MHz, CDCl 3 , TMS) $\delta 12.36,17.64,22.87,23.37,25.65,25.79,26.49$, 26.71, 27.27, 30.73, 30.93, 31.95, 33.97, 34.31, 34.58, 34.66, 35.54, 41.69, 45.08, 47.63, 49.44, 50.53, 50.94, 51.51, 75.97, 77.98, 167.48, 167.75, 174.50. HRMS (ES ${ }^{+}$) 573.3405; $\mathrm{C}_{29} \mathrm{H}_{45} \mathrm{~N}_{6} \mathrm{O}_{6}$ requires 573.3401, $[\mathrm{M}+\mathrm{H}]^{+}$.

\section{Synthesis of cholaphanes $4 a$ and $4 b$}

To a solution of $3 \alpha, 12 \alpha$-bis-(azidoacetyl)deoxycholate $2(0.1 \mathrm{~g}, 0.17 \mathrm{mmol})$ in $t$-BuOH $(75 \mathrm{ml})$, was added $(0.03 \mathrm{~g}, 0.17 \mathrm{mmol})$ of $\mathbf{3 a}$ or $\mathbf{3 b}$. To this solution, $\mathrm{CuSO}_{4}(10 \mathrm{~mol} \%)$ and sodium ascorbate $\left(20 \mathrm{~mol} \%\right.$ ) were added in $7.5 \mathrm{ml}$ of $\mathrm{H}_{2} \mathrm{O}$. The solution was stirred at $60{ }^{0} \mathrm{C}$ for $18 \mathrm{~h}$. The solution was evaporated under vacuum. The residue was washed with ethyl acetate to remove the starting material and residue was dissolved in $\mathrm{CHCl}_{3}$ and passed through a silica gel column. The organic layer was dried over $\mathrm{Na}_{2} \mathrm{SO}_{4}$ and evaporated under vacuum to give $\mathbf{4 a}(69 \%)$ / $\mathbf{4 b}(65 \%)$.

Analytical data for 4a: Melting point: $140{ }^{0} \mathrm{C}$ (decomp.). ${ }^{1} \mathrm{H}$ NMR (300 $\mathrm{MHz}, \mathrm{CDCl}_{3}$, TMS) $\delta 0.69$ (s, 3H, 18-Me), 0.79 (bs, 3H, 21-Me), 0.86 (s, 3H, 19-Me), 0.97-2.33 (26H, steroidal H), $3.64\left(\mathrm{~s}, 3 \mathrm{H}, \mathrm{OCH}_{3}\right), 4.75(\mathrm{~m}, 1 \mathrm{H}, 3 \beta-\mathrm{H}), 5.06-5.21(\mathrm{~m}, 9 \mathrm{H}, 12 \beta-\mathrm{H}$, $\mathrm{OCOCH}_{2} \mathrm{X} 2,-\mathrm{OCH}_{2} \mathrm{X}$ 2), 6.55-6.61 (m, 3H, ArH), 7.14 (bs, 1H, ArH), 7.84 (s, 2H, triazole-H); ${ }^{13} \mathrm{C} \mathrm{NMR}\left(75 \mathrm{MHz}, \mathrm{CDCl}_{3}\right.$, TMS) $\delta 12.37,17.80,22.89,23.44,25.50,25.95$, 26.25, 26.76, 27.37, 30.88, 31.08, 31.77, 34.02, 34.72, 35.49, 41.69, 45.17, 47.52, 49.35, 
$51.44,51.70,61.90,78.50,102.06,107.70,124.82,130.30,144.40,159.60,165.54$, 166.15, 174.82. HRMS $\left(\mathrm{ES}^{+}\right)$759.4089; $\mathrm{C}_{41} \mathrm{H}_{55} \mathrm{~N}_{6} \mathrm{O}_{8}$ requires 759.4081, $[\mathrm{M}+\mathrm{H}]^{+}$.

Analytical data for 4b: Melting point: $162{ }^{0} \mathrm{C}$ (decomp.). ${ }^{1} \mathrm{H}$ NMR (300 $\mathrm{MHz}, \mathrm{CDCl}_{3}$, TMS) $\delta 0.70$ (s, 3H, 18-Me), 0.80 (bs, 3H, 21-Me), 0.87 (s, 3H, 19-Me), 1.04-2.34 (26H, steroidal H), $3.64\left(\mathrm{~s}, 3 \mathrm{H}, \mathrm{OCH}_{3}\right), 4.76(\mathrm{~m}, 1 \mathrm{H}, 3 \beta-\mathrm{H}), 5.06-5.22(\mathrm{~m}, 9 \mathrm{H}, 12 \beta-\mathrm{H}$, $\mathrm{OCOCH}_{2}$ X 2, $-\mathrm{OCH}_{2} \mathrm{X}$ 2), 6.84-6.91 (m, 4H, ArH), 7.83 (bs, 1H, triazole-H), 7.87 (bs, $1 \mathrm{H}$, triazole-H); ${ }^{13} \mathrm{C}$ NMR $\left(75 \mathrm{MHz}, \mathrm{CDCl}_{3}\right.$, TMS $) \delta 12.09,17.52,22.60,23.19,25.20$, 25.66, 25.95, 26.48, 27.10, 30.61, 30.81, 31.51, 33.73, 33.90, 34.48, 35.23, 41.43, 44.92, 47.25, 49.07, 51.20, 51.40, 62.24, 77.20, 78.28, 115.66, 124.49, 144.51, 152.68, 165.20, 165.81, 174.50; HRMS $\left(\mathrm{ES}^{+}\right)$759.4099; $\mathrm{C}_{41} \mathrm{H}_{55} \mathrm{~N}_{6} \mathrm{O}_{8}$ requires 759.4081, $[\mathrm{M}+\mathrm{H}]^{+}$.

\section{Synthesis of acyclic compound 6}

To a solution of $3 \alpha, 12 \alpha$-bis-(azidoacetyl)deoxycholate $2(0.3 \mathrm{~g}, 0.52 \mathrm{mmol})$ in $t$-BuOH $(15 \mathrm{ml})$, was added $(0.11 \mathrm{~g}, 1.14 \mathrm{mmol})$ of phenyl acetylene. To this solution, $\mathrm{CuSO}_{4}(10$ mol \%) and sodium ascorbate $(20 \mathrm{~mol} \%)$ were added in $1.5 \mathrm{ml}$ of $\mathrm{H}_{2} \mathrm{O}$. The solution was stirred at $50{ }^{0} \mathrm{C}$ for $10 \mathrm{~h}$. The solution was evaporated under vacuum. The residue was purified by column chromatography on silica gel $(40 \%(\mathrm{v} / \mathrm{v})$ ethyl acetate in hexane and product obtained as white solid. Yield: $(80 \%)$. Melting point: $85-87{ }^{0} \mathrm{C}$. IR (KBr): $v_{\max } / \mathrm{cm}^{-1} 1742.10 ;{ }^{1} \mathrm{H}$ NMR $\left(300 \mathrm{MHz}, \mathrm{CDCl}_{3}\right.$, TMS) $\delta 0.68(\mathrm{~s}, 3 \mathrm{H}, 18-\mathrm{Me}), 0.80(\mathrm{~d}, \mathrm{~J}=$ $4.5 \mathrm{~Hz}, 3 \mathrm{H}, 21-\mathrm{Me}), 0.87$ (s, 3H, 19-Me), 0.94-2.38 (26H, steroidal H), 3.67 (s, 3H, $\left.\mathrm{OCH}_{3}\right), 4.77-4.82(\mathrm{~m}, 1 \mathrm{H}, 3 \beta-\mathrm{H}), 5.15(\mathrm{~s}, 1 \mathrm{H}, 12 \beta-\mathrm{H}), 5.05-5.18\left(\mathrm{~m}, 2 \mathrm{H},-\mathrm{OCOCH}_{2}\right)$, $5.30\left(\mathrm{~s}, 2 \mathrm{H},-\mathrm{OCOCH}_{2}\right), 7.29-7.46(\mathrm{~m}, 6 \mathrm{H}, \mathrm{ArH}), 7.75(\mathrm{~d}, \mathrm{~J}=7.8, \mathrm{~Hz}, 2 \mathrm{H}, \mathrm{ArH}), 7.82(\mathrm{~d}$, $\mathrm{J}=7.8 \mathrm{~Hz}, 2 \mathrm{H}, \mathrm{ArH}), 7.89\left(\mathrm{~s}, 1 \mathrm{H}\right.$, triazole-H), $8.07\left(\mathrm{~s}, 1 \mathrm{H}\right.$, triazole-H); ${ }^{13} \mathrm{C}$ NMR $(75$ $\left.\mathrm{MHz}, \mathrm{CDCl}_{3}, \mathrm{TMS}\right) \delta 12.08,17.58,22.59,23.14,25.12,25.58,26.00,26.48,27.10$, $30.66,30.88,31.49,33.73,33.87,34.45,34.54,35.24,41.46,44.98,47.31$, 49.12, 51.19, $51.33,51.45,77.21,78.39,121.31,121.44,125.62,125.71,128.02,128.27,128.66$, 128.81, 130.30, 130.39, 147.91, 148.15, 165.22, 165.85, 174.51. HRMS (ES $\left.{ }^{+}\right)$777.4335; $\mathrm{C}_{45} \mathrm{H}_{57} \mathrm{~N}_{6} \mathrm{O}_{6}$ requires $777.4340,[\mathrm{M}+\mathrm{H}]^{+}$.

\section{General procedure for methylation}

To a solution of $\mathbf{4 a}, \mathbf{4 b}$ or $\mathbf{6}(0.1 \mathrm{~mol})$ in dry $\mathrm{CHCl}_{3}$ was added $\mathrm{Mel}(0.6 \mathrm{~mol})$. The solution was stirred at room temperature for 3 days. The solution was diluted with $\mathrm{CHCl}_{3}$ and washed with $\mathrm{H}_{2} \mathrm{O}$, dried over $\mathrm{Na}_{2} \mathrm{SO}_{4}$ and evaporated under vacuum to give $\mathbf{5 a}, \mathbf{5 b}$ or 7 in quantitative yield.

Analytical data for 5a: Melting point: $167-168{ }^{0} \mathrm{C} .{ }^{1} \mathrm{H}$ NMR $\left(300 \mathrm{MHz}, \mathrm{CDCl}_{3}, \mathrm{TMS}\right) \delta$ 0.73 (s, 3H, 18-Me), 0.80 (bs, 3H, 21-Me), 0.89 (s, 3H, 19-Me), 0.97-2.36 (26H, steroidal $\mathrm{H}), 3.65\left(\mathrm{~s}, 3 \mathrm{H},-\mathrm{OCH}_{3}\right), 4.38\left(\mathrm{~s}, 3 \mathrm{H},-\mathrm{N}^{+} \mathrm{CH}_{3}\right), 4.46\left(\mathrm{~s}, 3 \mathrm{H},-\mathrm{N}^{+} \mathrm{CH}_{3}\right), 4.73(\mathrm{~m}, 1 \mathrm{H}, 3 \beta-\mathrm{H})$, $5.24(\mathrm{~s}, 1 \mathrm{H}, 12 \beta-\mathrm{H}), 5.54-6.05\left(\mathrm{~m}, 8 \mathrm{H},-\mathrm{OCOCH}_{2} \mathrm{X} 2,-\mathrm{OCH}_{2} \mathrm{X} 2\right), 6.63(\mathrm{bs}, 2 \mathrm{H}, \mathrm{ArH})$, 6.91-7.12 (m, 2H, ArH), $9.11\left(\mathrm{~s}, 1 \mathrm{H}\right.$, triazole-H), $9.28\left(\mathrm{~s}, 1 \mathrm{H}\right.$, triazole-H); ${ }^{13} \mathrm{C}$ NMR $(75$ $\mathrm{MHz}, \mathrm{CDCl}_{3}$, TMS) $\delta 12.26,17.61,22.69,23.31,25.61,25.78,25.93,26.61,27.26$, $29.27,30.67,31.06,31.48,33.86,34.14,34.63$, 35.39, 39.37, 39.48, 41.58, 45.12, 47.72, $49.30,51.48,54.12,54.37,58.83,77.21,79.11,100.82,109.79,129.65,130.55,131.69$, 
132.08, 139.88, 139.98, 158.32, 163.89, 164.58, 174.47; HRMS $\left(\mathrm{ES}^{+}\right)$915.3521; $\mathrm{C}_{43} \mathrm{H}_{60} \mathrm{~N}_{6} \mathrm{O}_{8} \mathrm{I}$ requires 915.3515, $[\mathrm{M}-\mathrm{I}]^{+}$.

Analytical data for 5b: Melting point: $170-172{ }^{0} \mathrm{C} .{ }^{1} \mathrm{H}$ NMR (300 $\mathrm{MHz}, \mathrm{CDCl}_{3}$, TMS) $\delta$ 0.73 (s, 3H, 18-Me), 0.81 (bs, 3H, 21-Me), 0.89 (s, 3H, 19-Me), 1.03-2.35 (26H, steroidal $\mathrm{H}), 3.66\left(\mathrm{~s}, 3 \mathrm{H},-\mathrm{OCH}_{3}\right), 4.39\left(\mathrm{~s}, 3 \mathrm{H},-\mathrm{N}^{+} \mathrm{CH}_{3}\right), 4.47\left(\mathrm{~s}, 3 \mathrm{H},-\mathrm{N}^{+} \mathrm{CH}_{3}\right), 4.73$ (bs, $1 \mathrm{H}, 3 \beta-$ $\mathrm{H}), 5.25(\mathrm{~s}, 1 \mathrm{H}, 12 \beta-\mathrm{H}), 5.50-6.01\left(\mathrm{~m}, 8 \mathrm{H},-\mathrm{OCOCH}_{2} \mathrm{X} 2,-\mathrm{OCH}_{2} \mathrm{X} 2\right), 7.00(\mathrm{bs}, 4 \mathrm{H}$, $\mathrm{ArH}), 9.21\left(\mathrm{~s}, 1 \mathrm{H}\right.$, triazole-H), $9.41(\mathrm{~s}, 1 \mathrm{H}$, triazole- $\mathrm{H}) ;{ }^{13} \mathrm{C} \mathrm{NMR}\left(75 \mathrm{MHz}, \mathrm{CDCl}_{3}\right.$, TMS) $\delta 12.03,17.43,22.38,23.15,25.34,25.61,25.99,26.25,26.98,30.85,31.60$, 31.82 , 33.60, 33.79, 34.53, 35.27, 39.47, 39.64, 41.28, 44.86, 47.10, 49.01, 51.26, 54.34, $59.14,59.47,77.20,78.88,116.22,131.56,139.58,151.85,163.51,164.18,174.25$; HRMS (ES ${ }^{+}$915.3525; $\mathrm{C}_{43} \mathrm{H}_{60} \mathrm{~N}_{6} \mathrm{O}_{8} \mathrm{I}$ requires 915.3515, [M - I] $]^{+}$.

Analytical data for 7: Melting point: 97-98 ${ }^{0} \mathrm{C} .{ }^{1} \mathrm{H}$ NMR (300 MHZ, $\left.\mathrm{CDCl}_{3}, \mathrm{TMS}\right) \delta 0.76$ (s, 3H, 18-Me), 0.84 (d, J = $5.7 \mathrm{~Hz}, 3 \mathrm{H}, 21-\mathrm{Me}), 0.92$ (s, 3H, 19-Me), 0.98-2.43 (26H, steroidal $\mathrm{H}), 3.67\left(\mathrm{~s}, 3 \mathrm{H},-\mathrm{OCH}_{3}\right), 4.39\left(\mathrm{~s}, 3 \mathrm{H},-\mathrm{N}^{+} \mathrm{CH}_{3}\right), 4.42\left(\mathrm{~s}, 3 \mathrm{H},-\mathrm{N}^{+} \mathrm{CH}_{3}\right), 4.79-4.84$ $(\mathrm{m}, 1 \mathrm{H}, 3 \beta-\mathrm{H}), 5.32(\mathrm{~s}, 1 \mathrm{H}, 12 \beta-\mathrm{H}), 5.68-6.40\left(\mathrm{~m}, 4 \mathrm{H},-\mathrm{OCOCH}_{2} \mathrm{X} 2\right), 7.38-7.91(\mathrm{~m}$, $10 \mathrm{H}, \mathrm{ArH}), 9.43\left(\mathrm{~s}, 1 \mathrm{H}\right.$, triazole-H), $9.51(\mathrm{~s}, 1 \mathrm{H}$, triazole- $\mathrm{H}) ;{ }^{13} \mathrm{C}$ NMR $\left(75 \mathrm{MHz}, \mathrm{CDCl}_{3}\right.$, TMS) $\delta 11.88,17.13,22.32,22.89,25.20,25.41,25.64,26.20,26.39,26.85,30.18$, $30.62,31.13,33.41,33.81,34.10,34.15,34.96,38.80,39.05,41.17,44.70,47.31,48.94$, $51.04,53.51,53.75,77.21,78.82,121.32,121.45,125.04,125.18,128.32,128.97$, $129.01,129.11,129.19,129.29,130.07,130.60,131.32,131.48,142.54,142.71,163.71$, 164.11, 174.05; HRMS (ES ${ }^{+}$933.3775; $\mathrm{C}_{47} \mathrm{H}_{62} \mathrm{~N}_{6} \mathrm{O}_{6} \mathrm{I}$ requires 933.3776, [M - I] $]^{+}$.

\section{General procedure for anion exchange of di-iodide salts of receptors with $\mathrm{NH}_{4} \mathbf{P F}_{6}$}

Di-iodide salt $\left(100 \mathrm{mg}\right.$ ) of receptor (in $5 \mathrm{~mL} \mathrm{CHCl}_{3}$ ) was added to saturated methanolic solution of $\mathrm{NH}_{4} \mathrm{PF}_{6}(3 \mathrm{~mL})$ and stirred for $2 \mathrm{~h}$. White precipitate of product obtained was filtered and washed with methanol and then dried under vacuum. Yield: $85-90 \%$

Analytical data for 5a.(PF $)$ : Melting point: $174{ }^{0} \mathrm{C}$ (decomp.). ${ }^{1} \mathrm{H}$ NMR (300 MHZ, $\mathrm{CDCl}_{3}$, TMS) $\delta$ 0.74-0.88 (m, 9H, 18-Me, 19-Me and 21-Me), 1.02-2.17 (26H, steroidal $\mathrm{H}), 3.64\left(\mathrm{~s}, 3 \mathrm{H},-\mathrm{OCH}_{3}\right), 4.26\left(\mathrm{bs}, 6 \mathrm{H},-\mathrm{N}^{+} \mathrm{CH}_{3}\right), 4.70(\mathrm{bs}, 1 \mathrm{H}, 3 \beta-\mathrm{H}), 5.23-5.61(\mathrm{~m}, 9 \mathrm{H}$, $12 \beta-\mathrm{H},-\mathrm{OCOCH}_{2} \mathrm{X} 2,-\mathrm{OCH}_{2} \mathrm{X}$ 2), 6.54 (bs, 3H, $\mathrm{ArH}$ ), 7.03 (bs, $\left.1 \mathrm{H}, \mathrm{ArH}\right), 8.64$ (bs, $2 \mathrm{H}$, triazole-H); HRMS $\left(\mathrm{ES}^{+}\right)$933.4142; $\mathrm{C}_{43} \mathrm{H}_{60} \mathrm{~N}_{6} \mathrm{O}_{8} \mathrm{PF}_{6}$ requires 933.4114, $\left[\mathrm{M}-\mathrm{PF}_{6}\right]^{+}$.

Analytical data for 5b.(PF $\mathbf{6})$ : Melting point: $180-181{ }^{0} \mathrm{C} .{ }^{1} \mathrm{H}$ NMR $\left(300 \mathrm{MHz}, \mathrm{CDCl}_{3}\right.$, TMS) $\delta$ 0.72-0.88 (m, 9H, 18-Me, 19-Me and 21-Me), 0.92-2.23 (26H, steroidal H), 3.65 (s, $\left.3 \mathrm{H},-\mathrm{OCH}_{3}\right), 4.27$ (bs, $\left.6 \mathrm{H},-\mathrm{N}^{+} \mathrm{CH}_{3}\right), 4.72(\mathrm{bs}, 1 \mathrm{H}, 3 \beta-\mathrm{H}), 5.14-5.61(\mathrm{~m}, 9 \mathrm{H}, 12 \beta-\mathrm{H},-$ $\mathrm{OCOCH}_{2} \mathrm{X} 2$, - $-\mathrm{OCH}_{2} \mathrm{X}$ 2), 6.80 (bs, $\left.4 \mathrm{H}, \mathrm{ArH}\right), 8.55$ (bs, $2 \mathrm{H}$, triazole-H); HRMS $\left(\mathrm{ES}^{+}\right.$) 933.4108; $\mathrm{C}_{43} \mathrm{H}_{60} \mathrm{~N}_{6} \mathrm{O}_{8} \mathrm{PF}_{6}$ requires 933.4114, $\left[\mathrm{M}-\mathrm{PF}_{6}\right]^{+}$.

Analytical data for 7.(PF $)$ : Melting point: $105-107{ }^{0} \mathrm{C} .{ }^{1} \mathrm{H}$ NMR $\left(300 \mathrm{MHz}, \mathrm{CDCl}_{3}\right.$, TMS) $\delta 0.68$ (s, 3H, 18-Me), 0.81 (d, J = 5.4 Hz, 3H, 21-Me), 0.91 (s, 3H, 19-Me), 0.92$2.44\left(26 \mathrm{H}\right.$, steroidal H), $3.66\left(\mathrm{~s}, 3 \mathrm{H},-\mathrm{OCH}_{3}\right), 4.21\left(\mathrm{~s}, 3 \mathrm{H},-\mathrm{N}^{+} \mathrm{CH}_{3}\right), 4.27\left(\mathrm{~s}, 3 \mathrm{H},-\mathrm{N}^{+} \mathrm{CH}_{3}\right)$, 4.77-4.85 (m, $1 \mathrm{H}, 3 \beta-\mathrm{H}), 5.15-5.67\left(\mathrm{~m}, 5 \mathrm{H},-\mathrm{OCOCH}_{2} \mathrm{X} 2\right.$ and $\left.12 \beta-\mathrm{H}\right), 7.34-7.84(\mathrm{~m}$, 
$10 \mathrm{H}, \quad \mathrm{ArH}), 8.53(\mathrm{~s}, 1 \mathrm{H}), 8.66\left(\mathrm{~s}, 1 \mathrm{H}\right.$, triazole-H); HRMS $\left(\mathrm{ES}^{+}\right)$951.4361; $\mathrm{C}_{47} \mathrm{H}_{62} \mathrm{~N}_{6} \mathrm{O}_{6} \mathrm{PF}_{6}$ requires 951.4407, $\left[\mathrm{M}-\mathrm{PF}_{6}\right]^{+}$.

\section{${ }^{1}$ H NMR Titration method}

All NMR experiments were performed on a Bruker DPX300 (300 MHz) spectrometer at $298 \mathrm{~K}$. A solution $(10 \mathrm{mM})$ of receptor in $\mathrm{CDCl}_{3}$ was titrated with aliquots from stock solution of tetrabutylammonium salt $(50-60 \mathrm{mM})$ in the same solvent. The chemical shift changes of the $\mathrm{C}(5)$-protons of triazolium units in receptor were monitored. The association constants Ka were calculated using the WinEQNMR computer program. Every titration was repeated at least once until consistent results were obtained. 


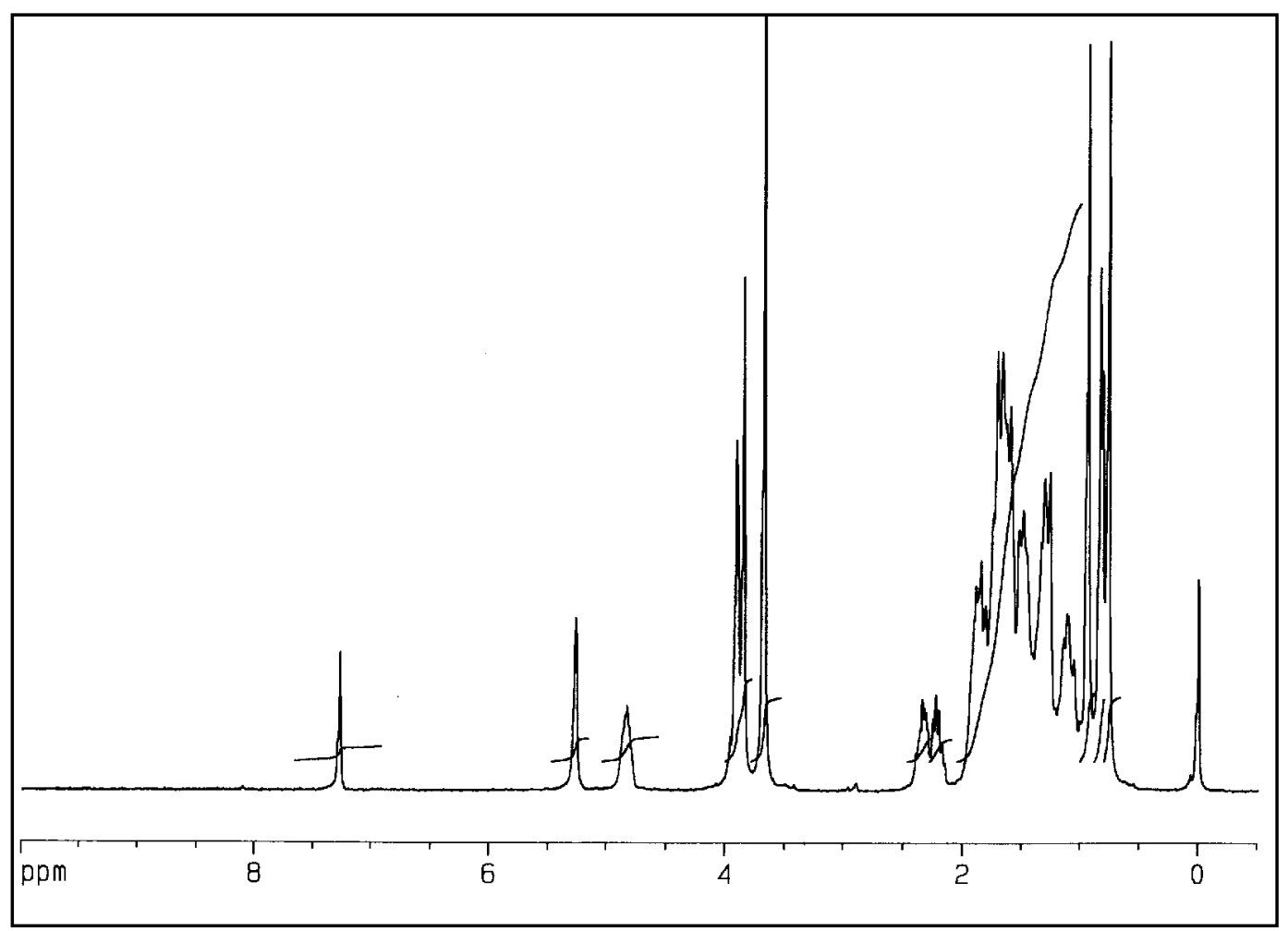

${ }^{1}$ H-NMR spectrum of compound 2

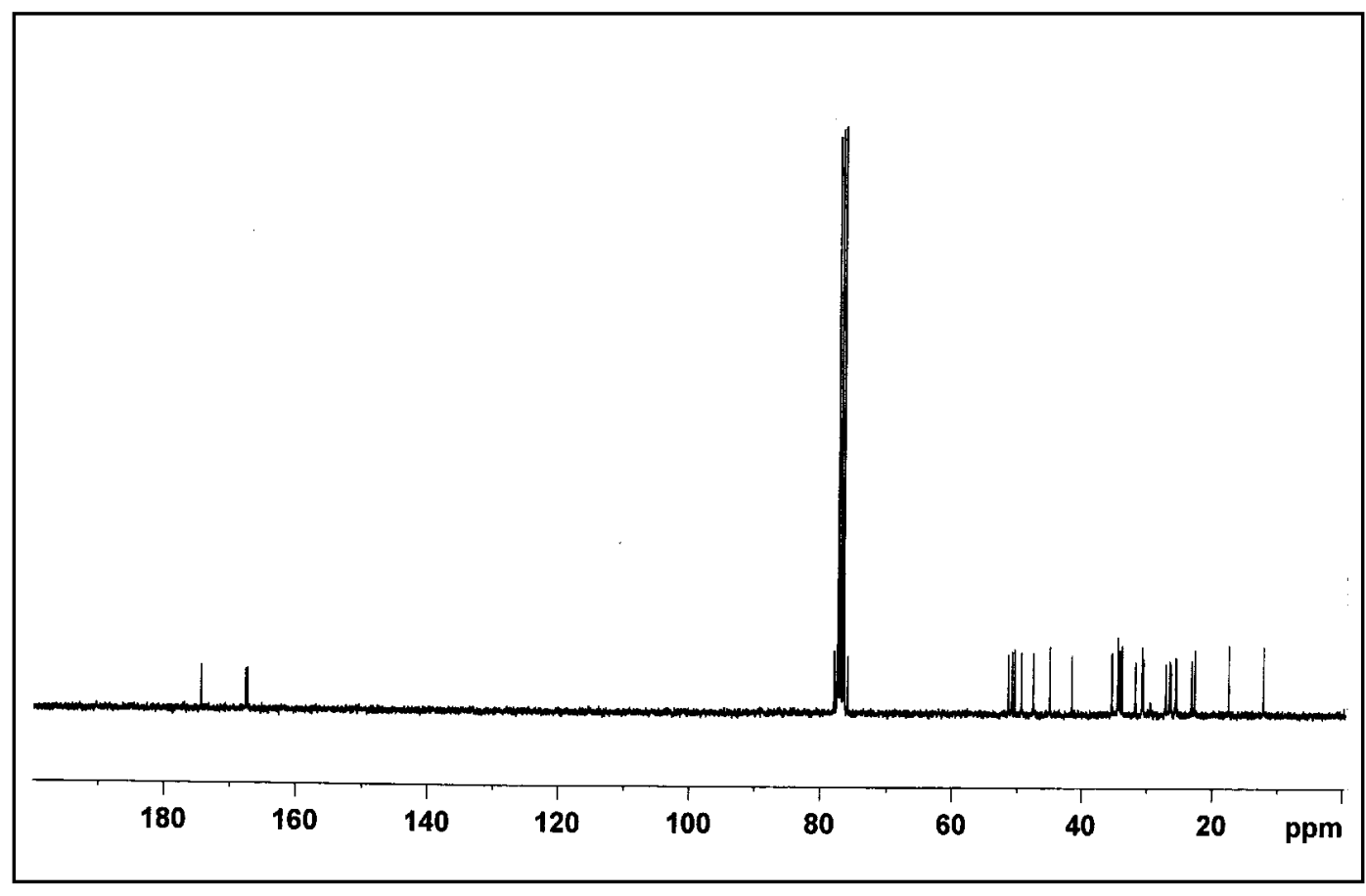

${ }^{13} \mathrm{C}-\mathrm{NMR}$ spectrum of compound 2 


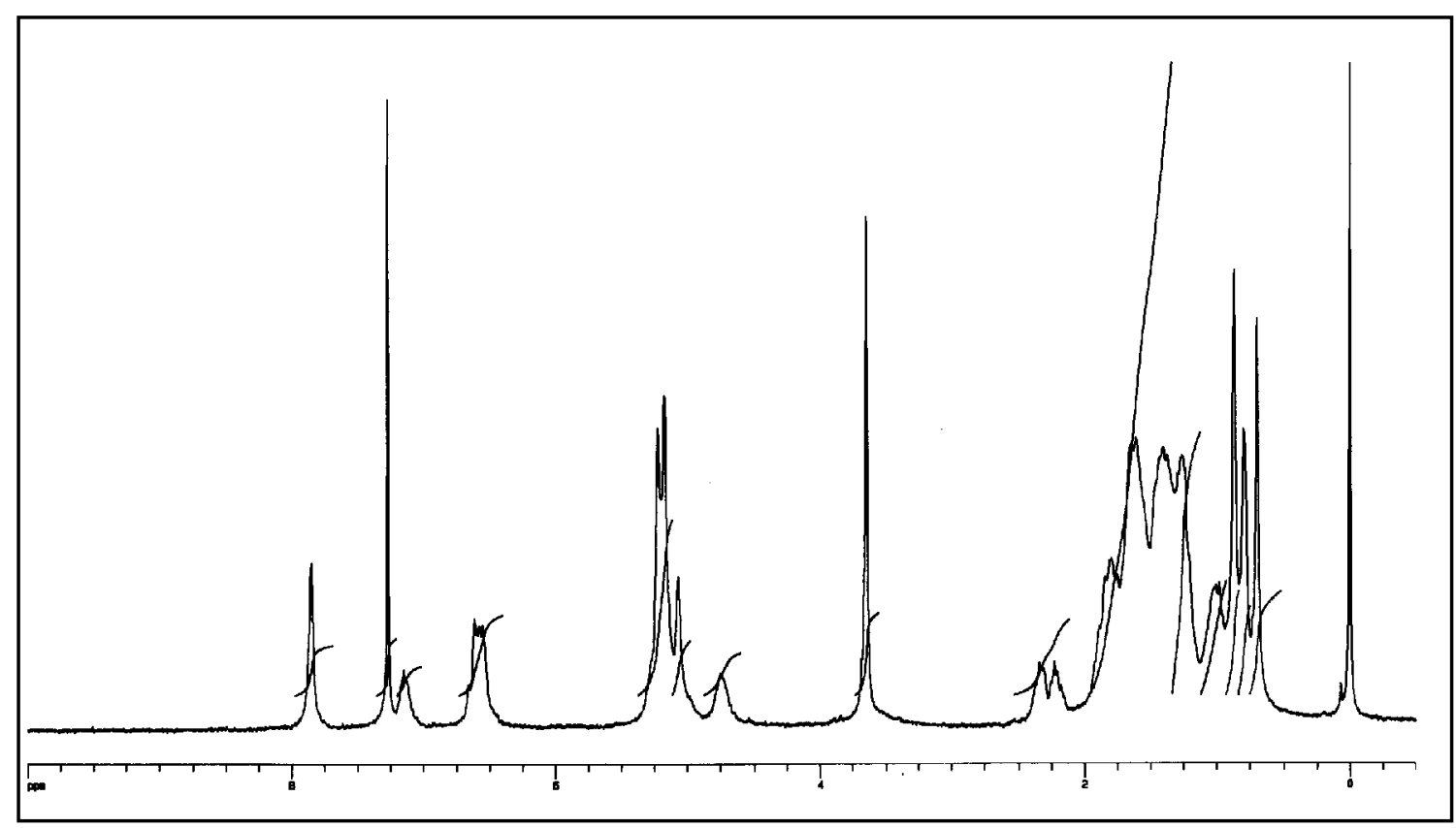

${ }^{1}$ H-NMR spectrum of compound $\mathbf{4 a}$

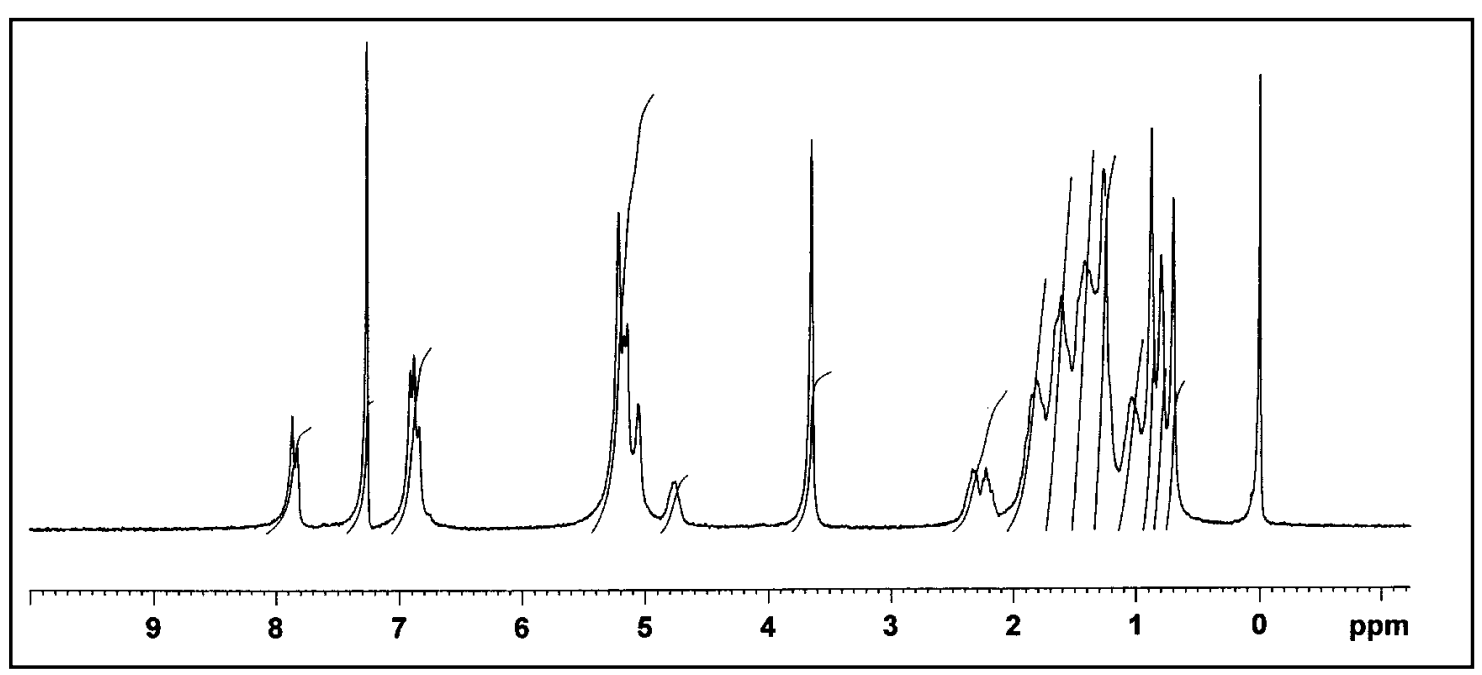

${ }^{1} \mathrm{H}-\mathrm{NMR}$ spectrum of compound $\mathbf{4 b}$ 


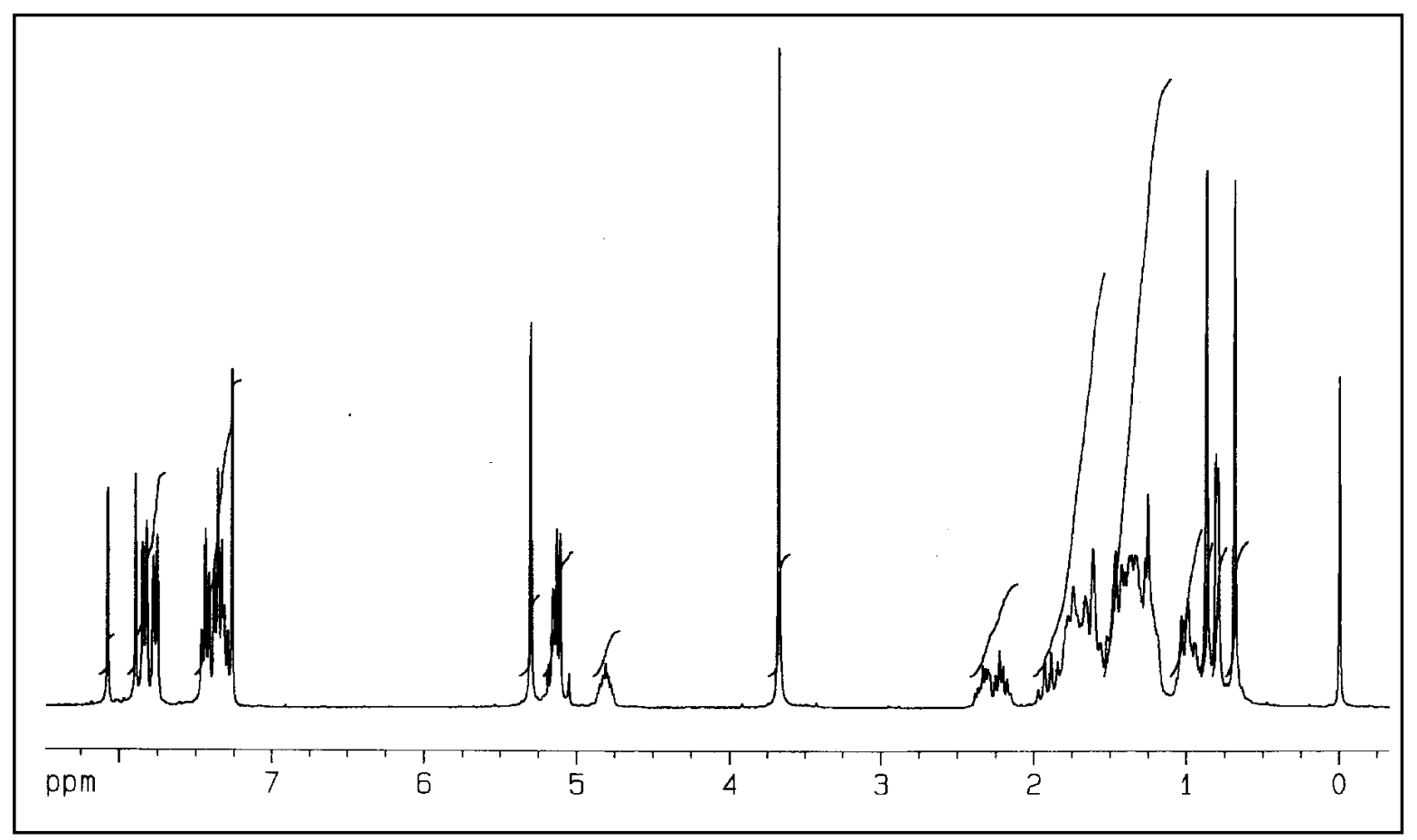

${ }^{1} \mathrm{H}-\mathrm{NMR}$ spectrum of compound $\mathbf{6}$

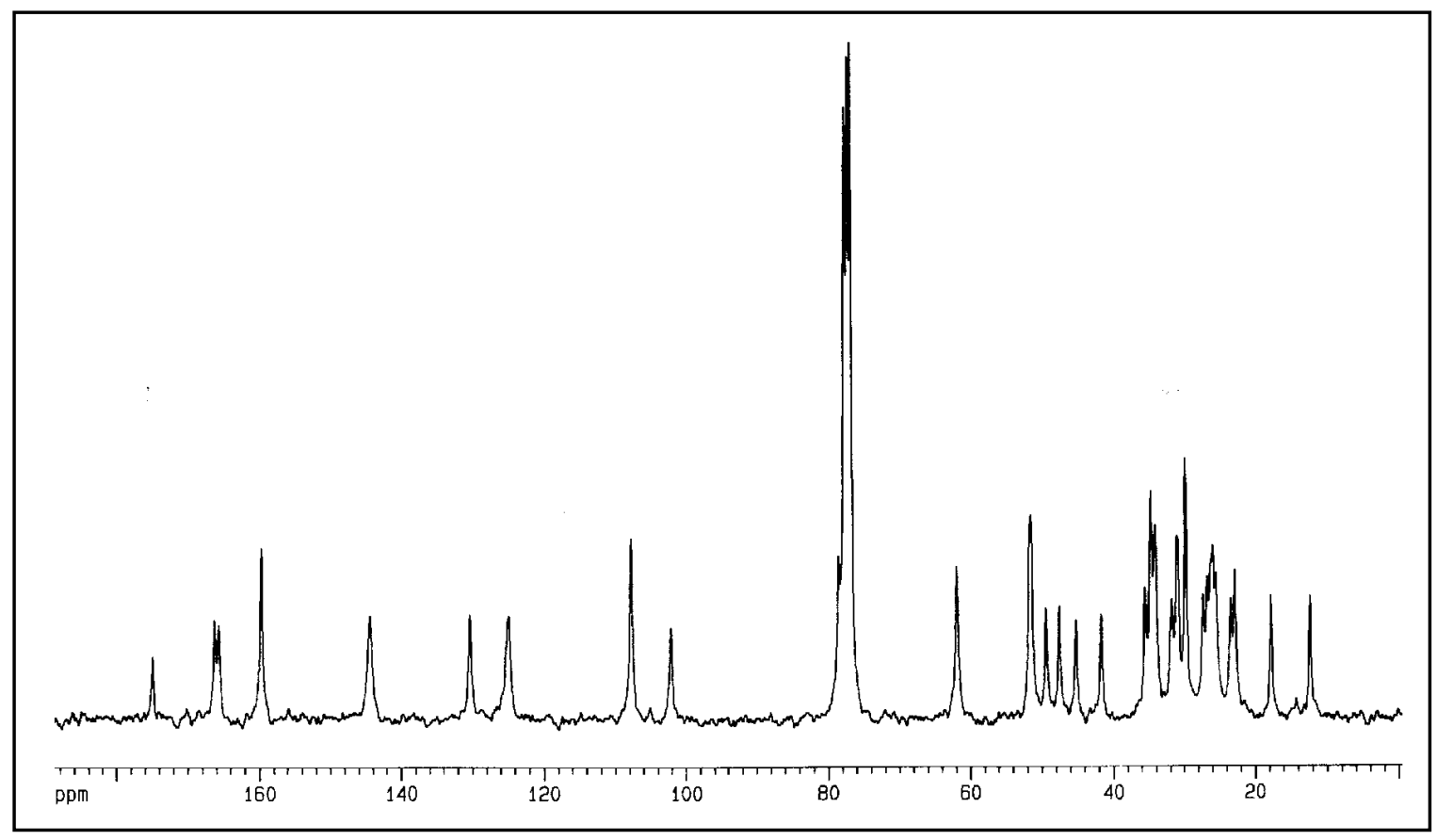

${ }^{13} \mathrm{C}$-NMR spectrum of compound $\mathbf{4 a}$ 


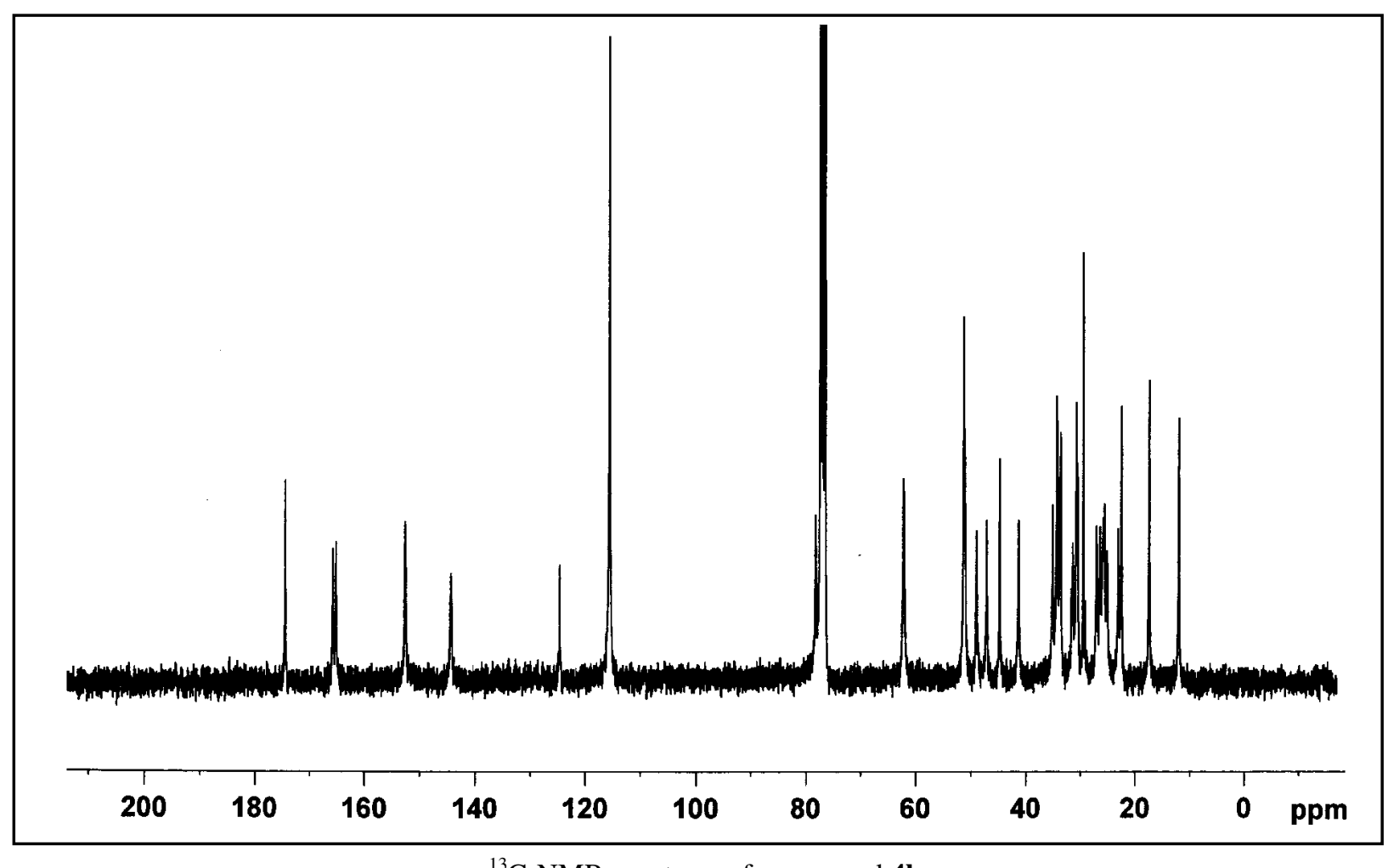

${ }^{13} \mathrm{C}-\mathrm{NMR}$ spectrum of compound $\mathbf{4 b}$

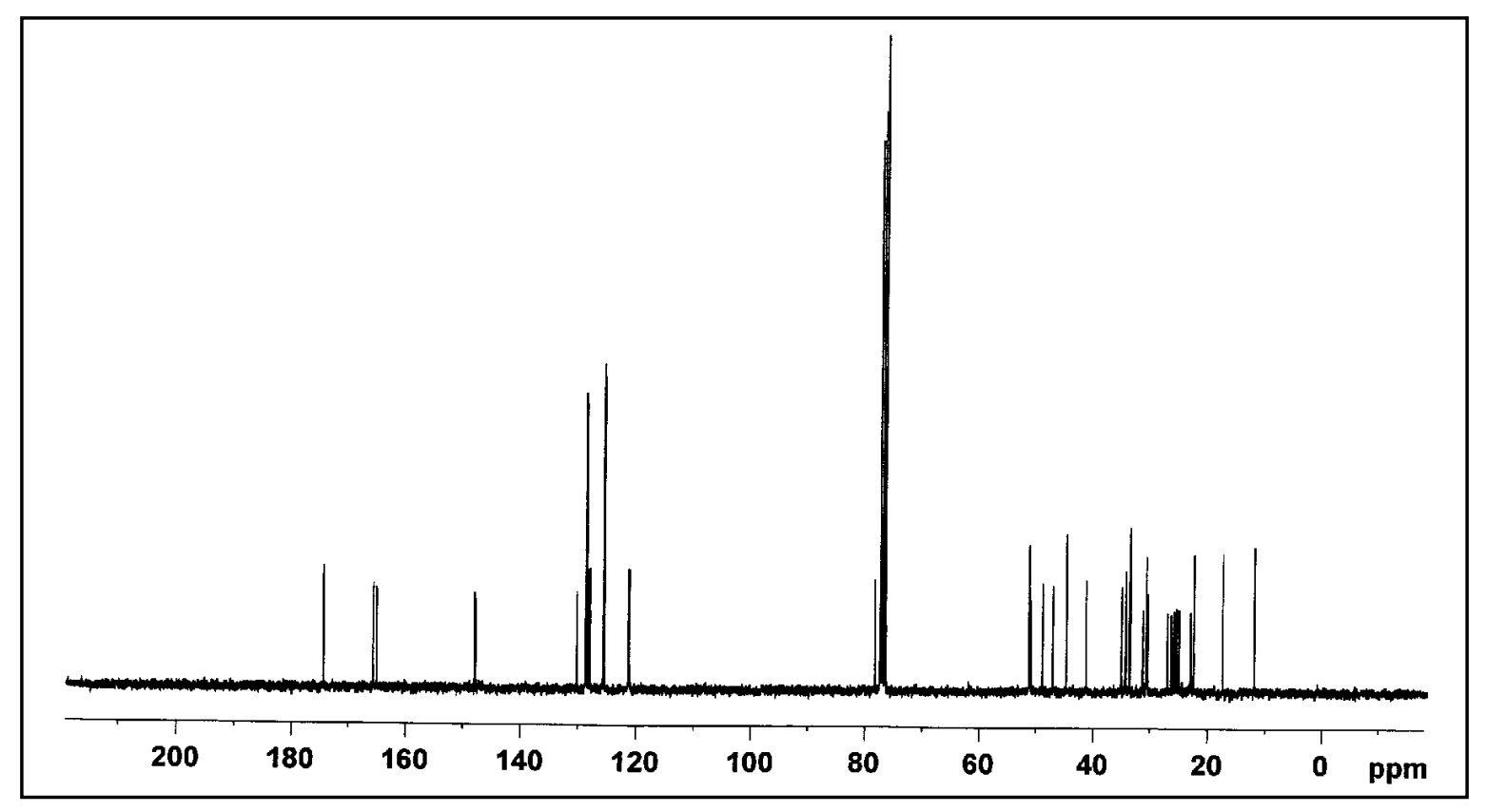

${ }^{13} \mathrm{C}-\mathrm{NMR}$ spectrum of compound 6 


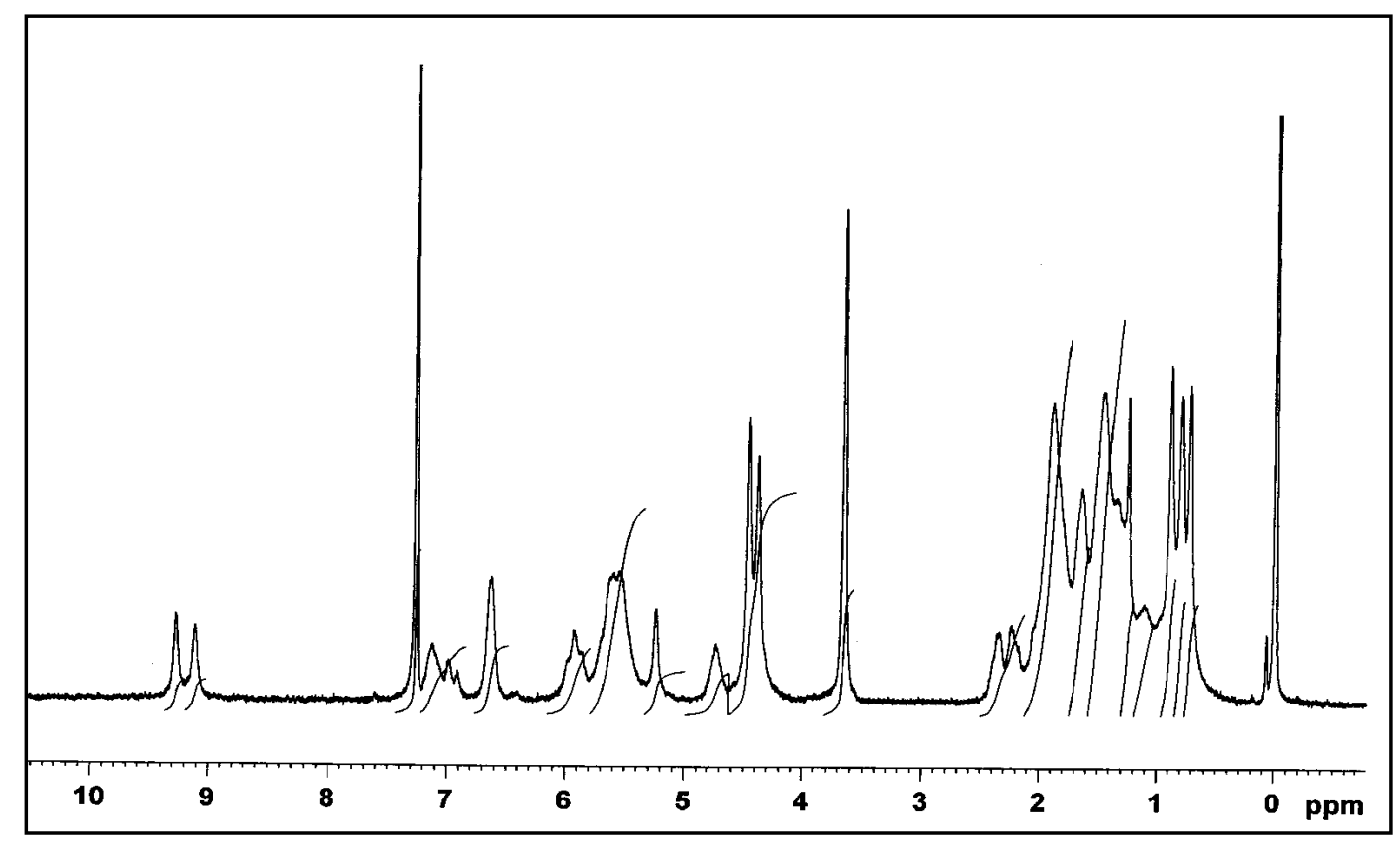

${ }^{1}$ H-NMR spectrum of compound $\mathbf{5 a - ( I )}{ }_{2}$

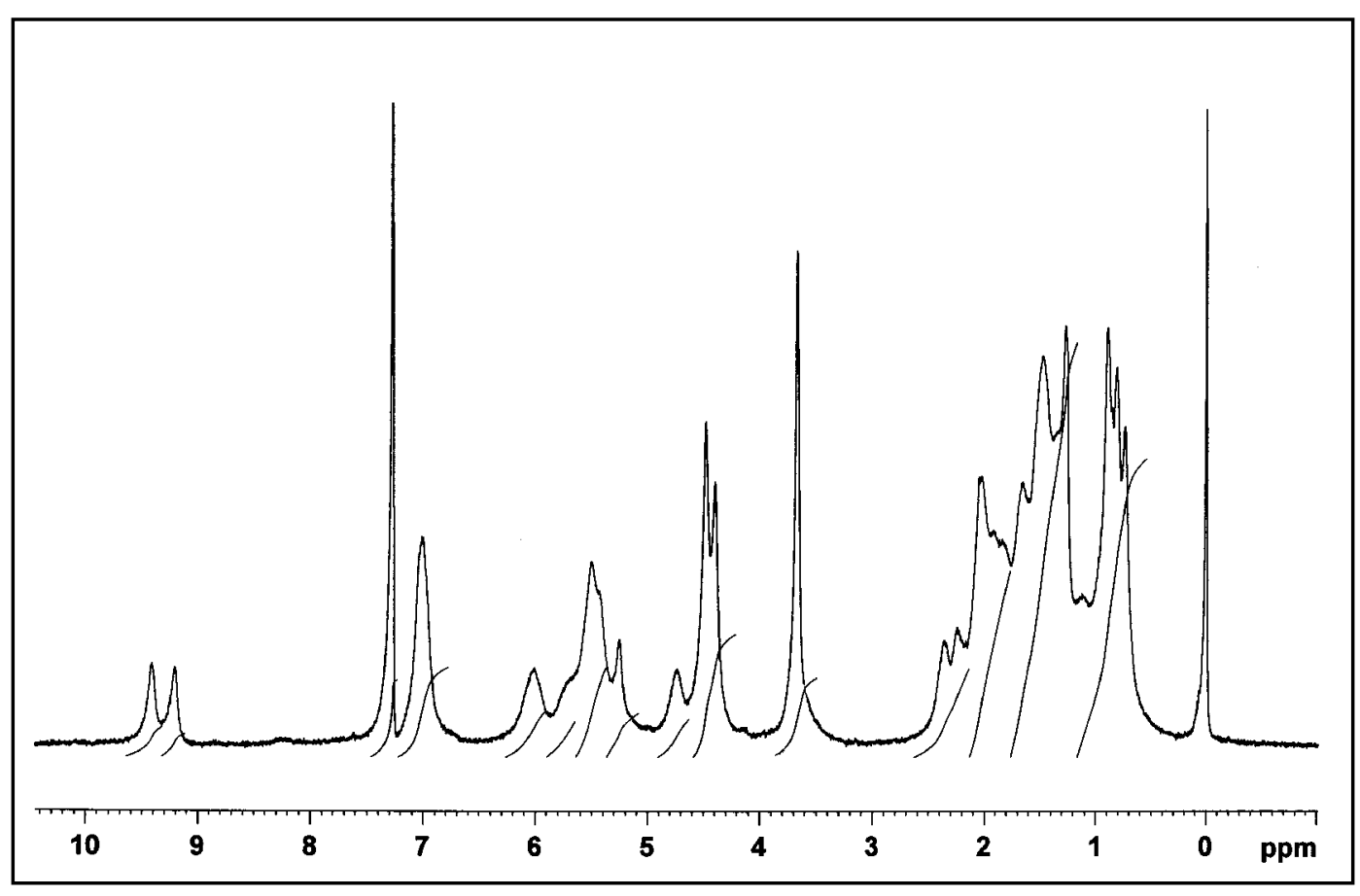

${ }^{1}$ H-NMR spectrum of compound $\mathbf{5 b}$-(I) $)_{2}$ 


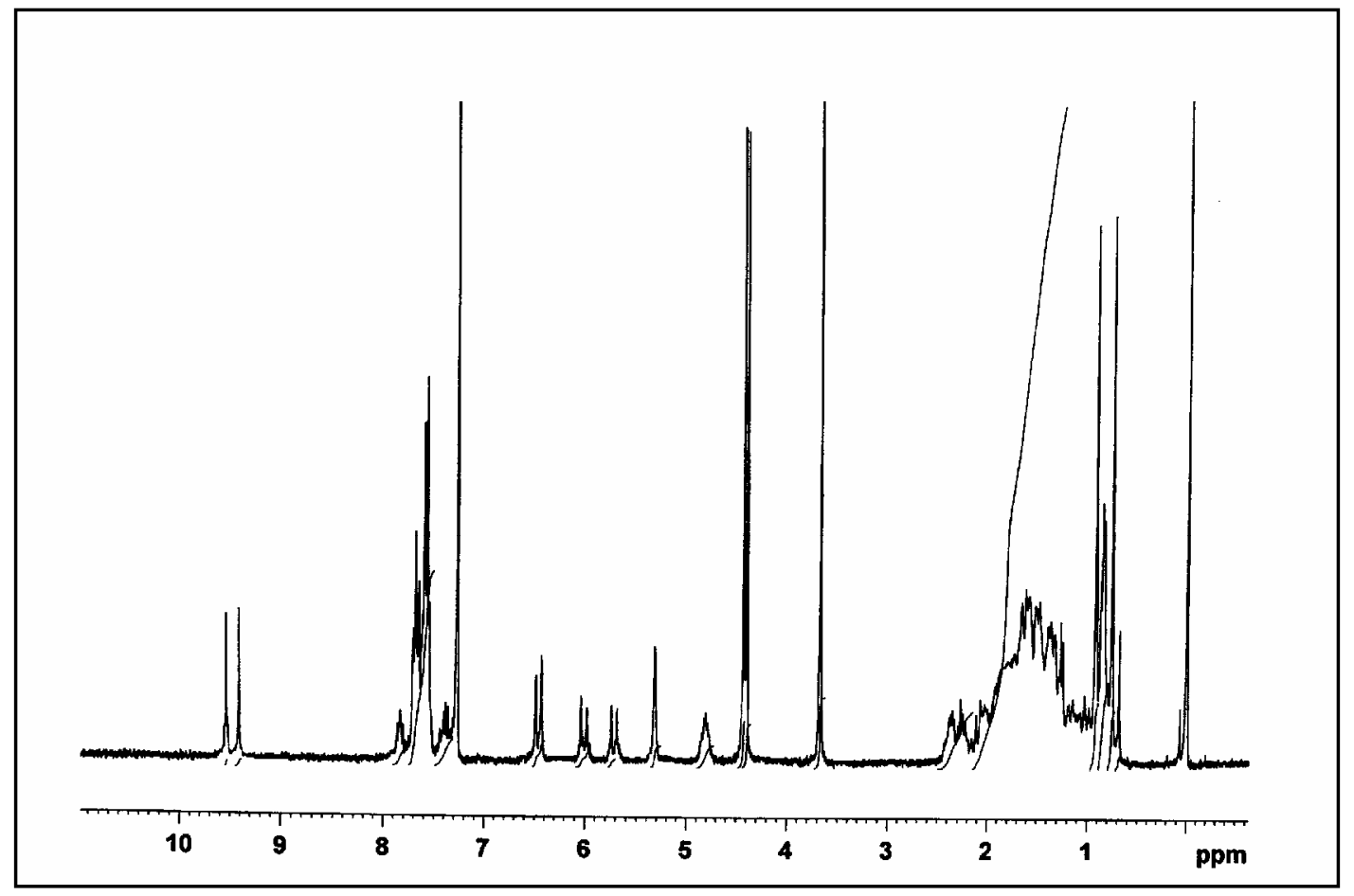

${ }^{1} \mathrm{H}-\mathrm{NMR}$ spectrum of compound 7-(I) ${ }_{2}$

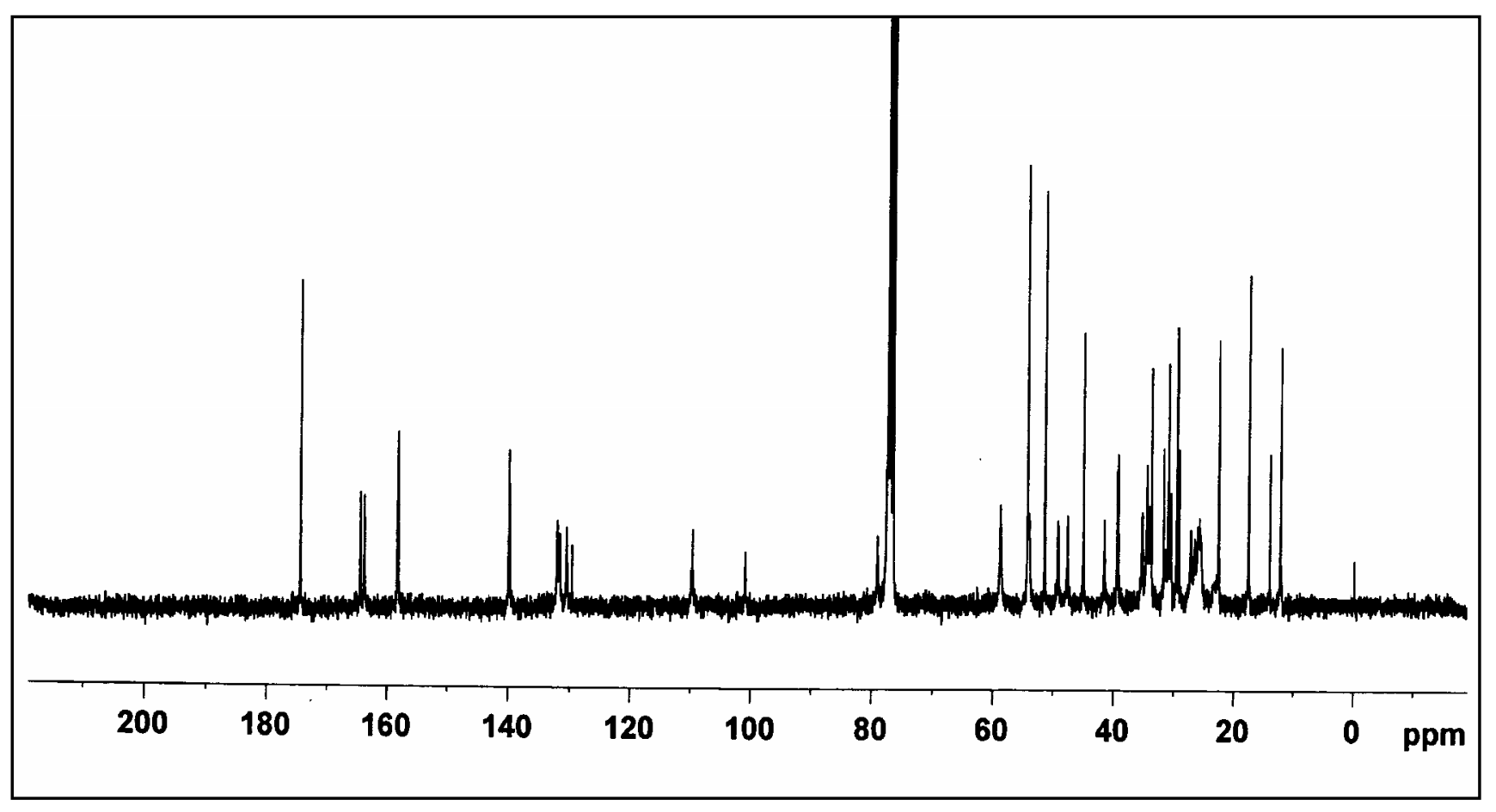

${ }^{13} \mathrm{C}$-NMR spectrum of compound $\mathbf{5 a}-(\mathbf{I})_{2}$ 


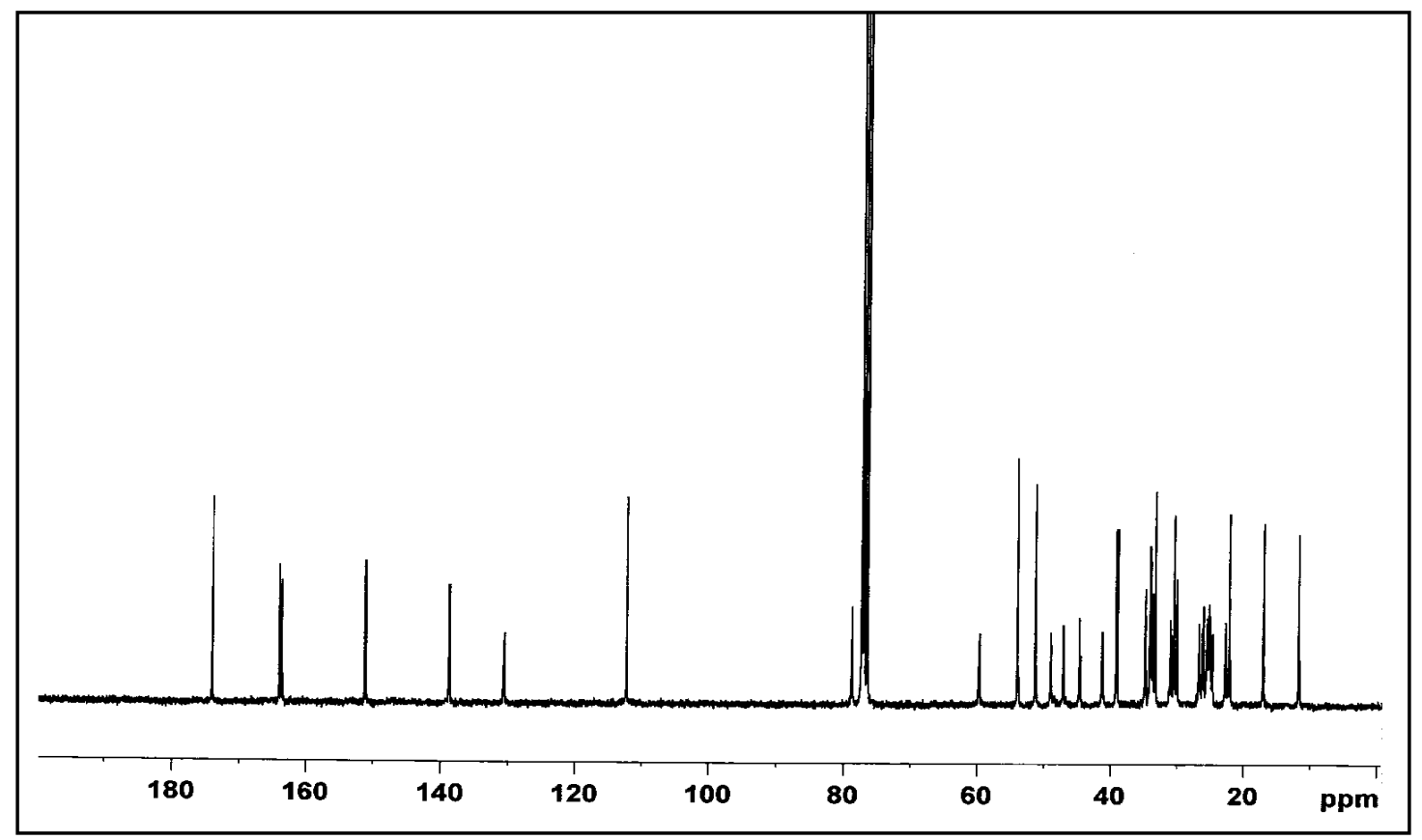

${ }^{13} \mathrm{C}-\mathrm{NMR}$ spectrum of compound $\mathbf{5 b}$-(I) $)_{2}$

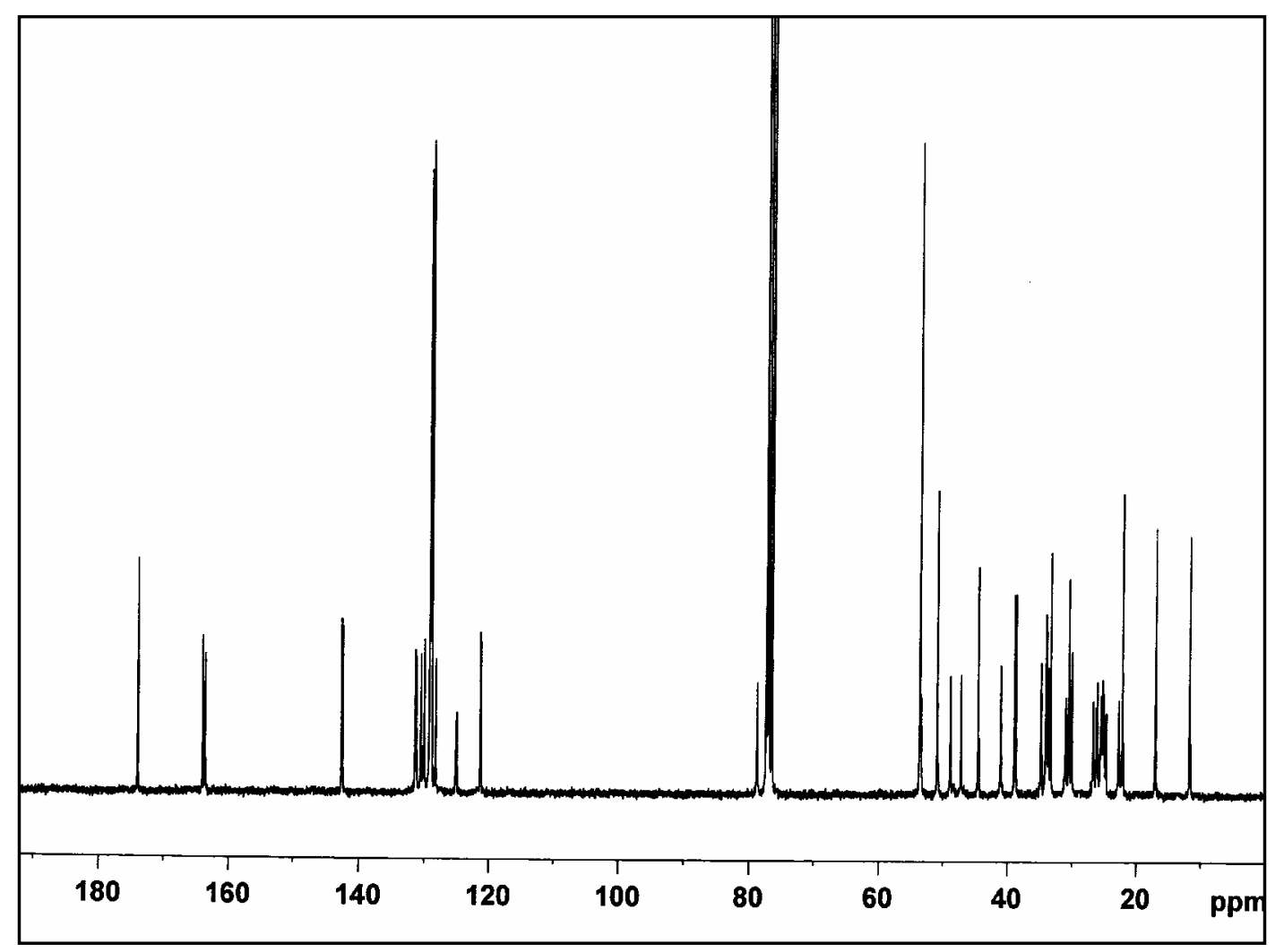

${ }^{13} \mathrm{C}-\mathrm{NMR}$ spectrum of compound $7-(\mathbf{I})_{2}$ 


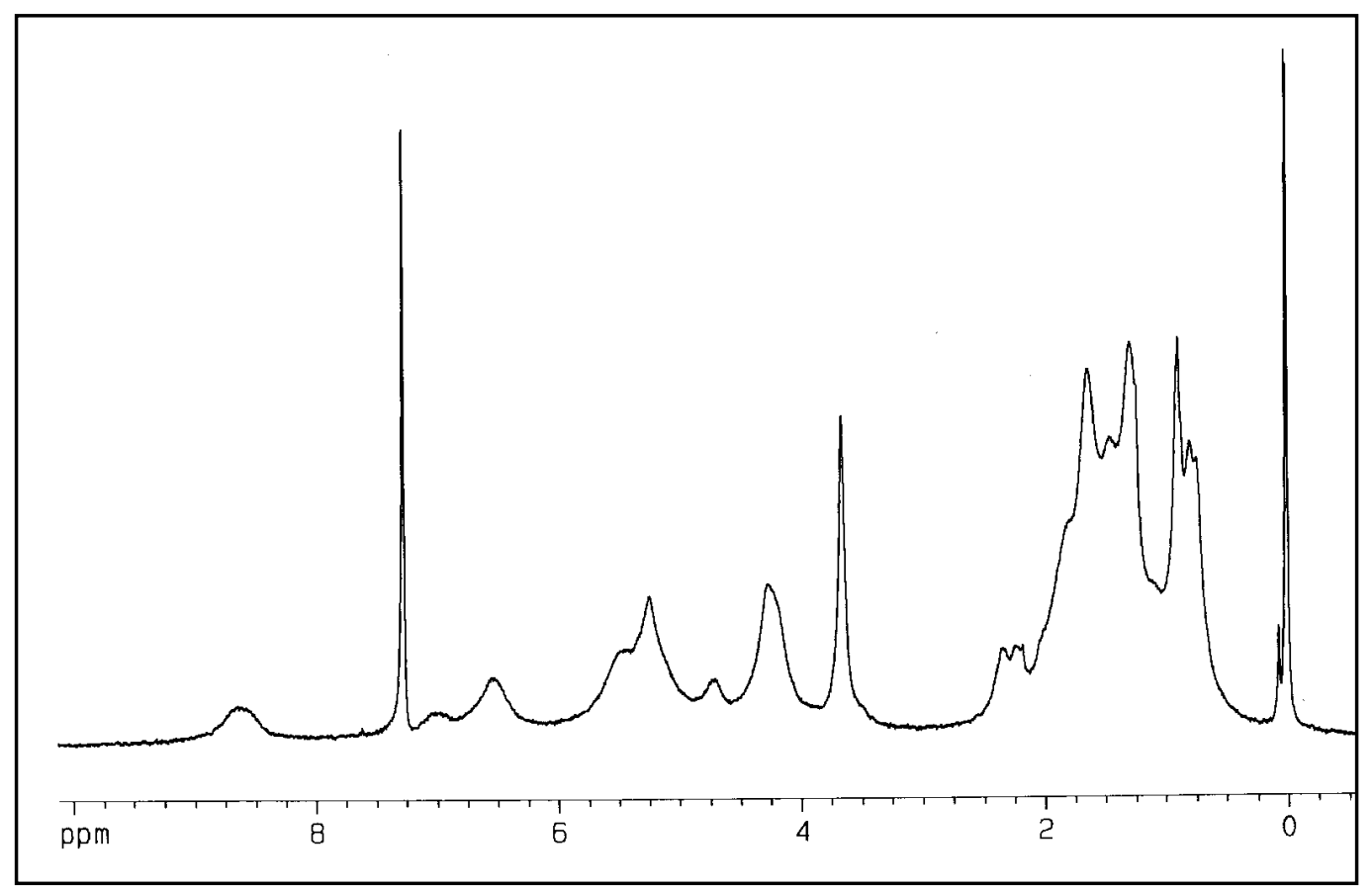

${ }^{1}$ H-NMR spectrum of compound $\mathbf{5 a}-\left(\mathbf{P F}_{\mathbf{6}}\right)_{2}$

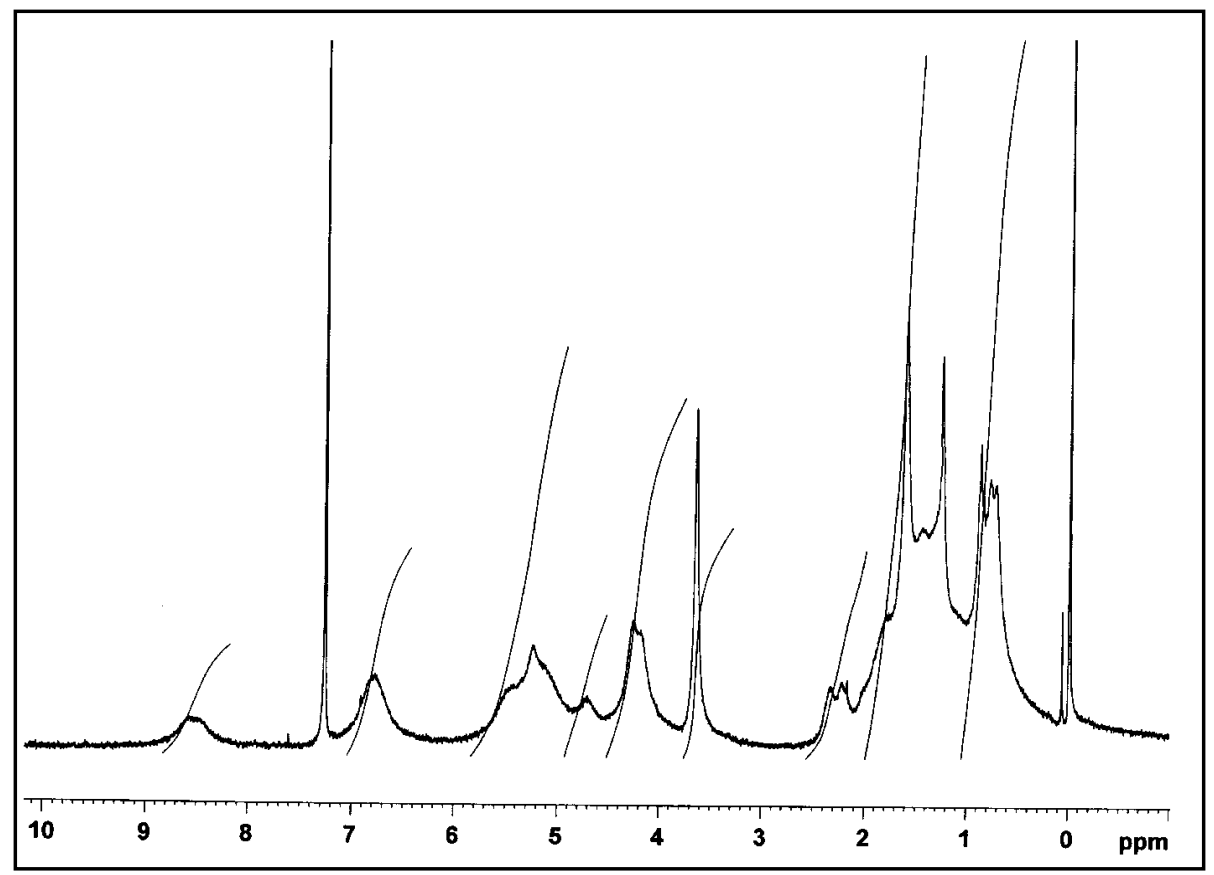

${ }^{1}$ H-NMR spectrum of compound $\mathbf{5 b}-\left(\mathbf{P F}_{\mathbf{6}}\right)_{\mathbf{2}}$ 


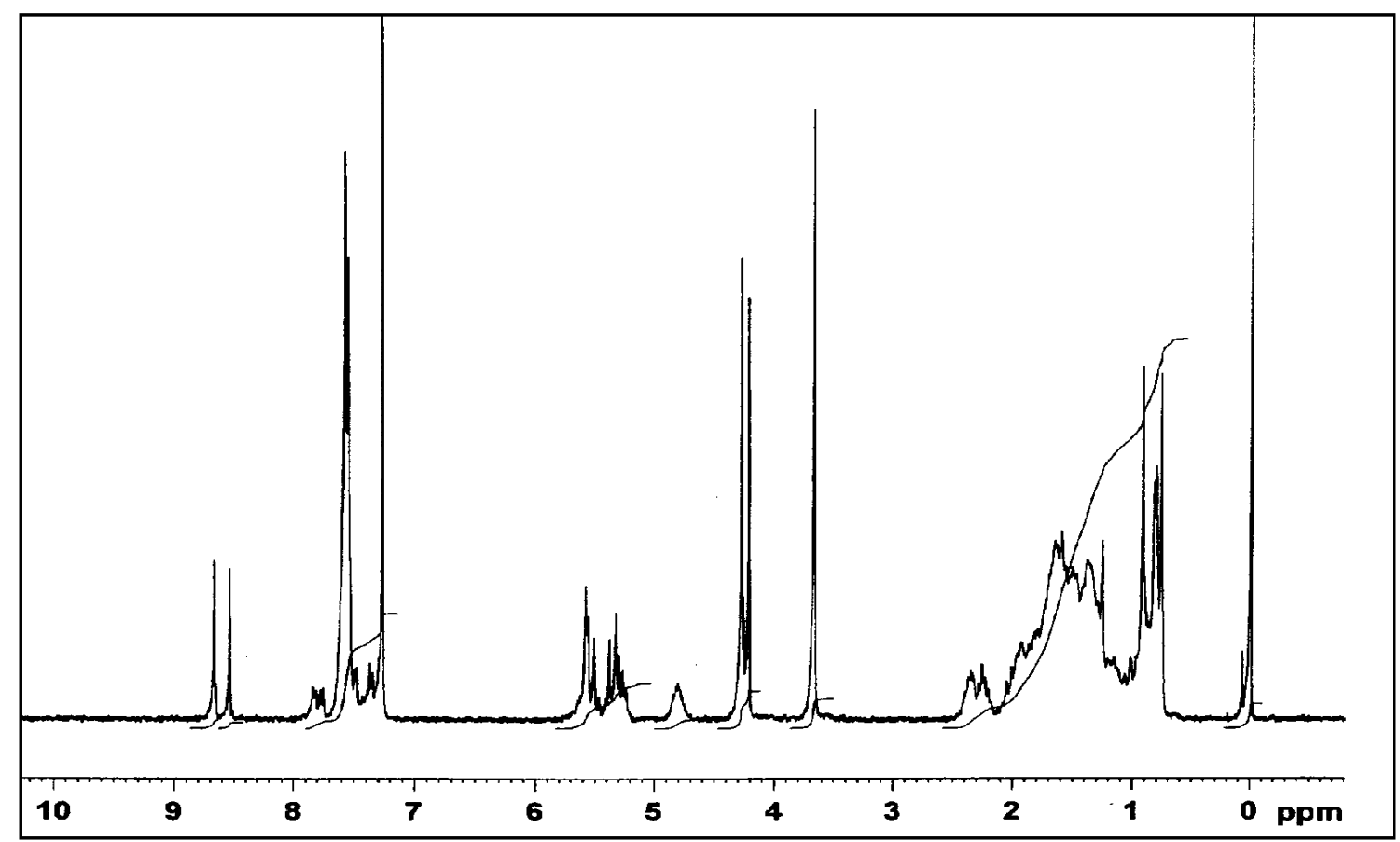

${ }^{1}$ H-NMR spectrum of compound 7-( $\left.\mathbf{P F}_{\mathbf{6}}\right)_{2}$ 


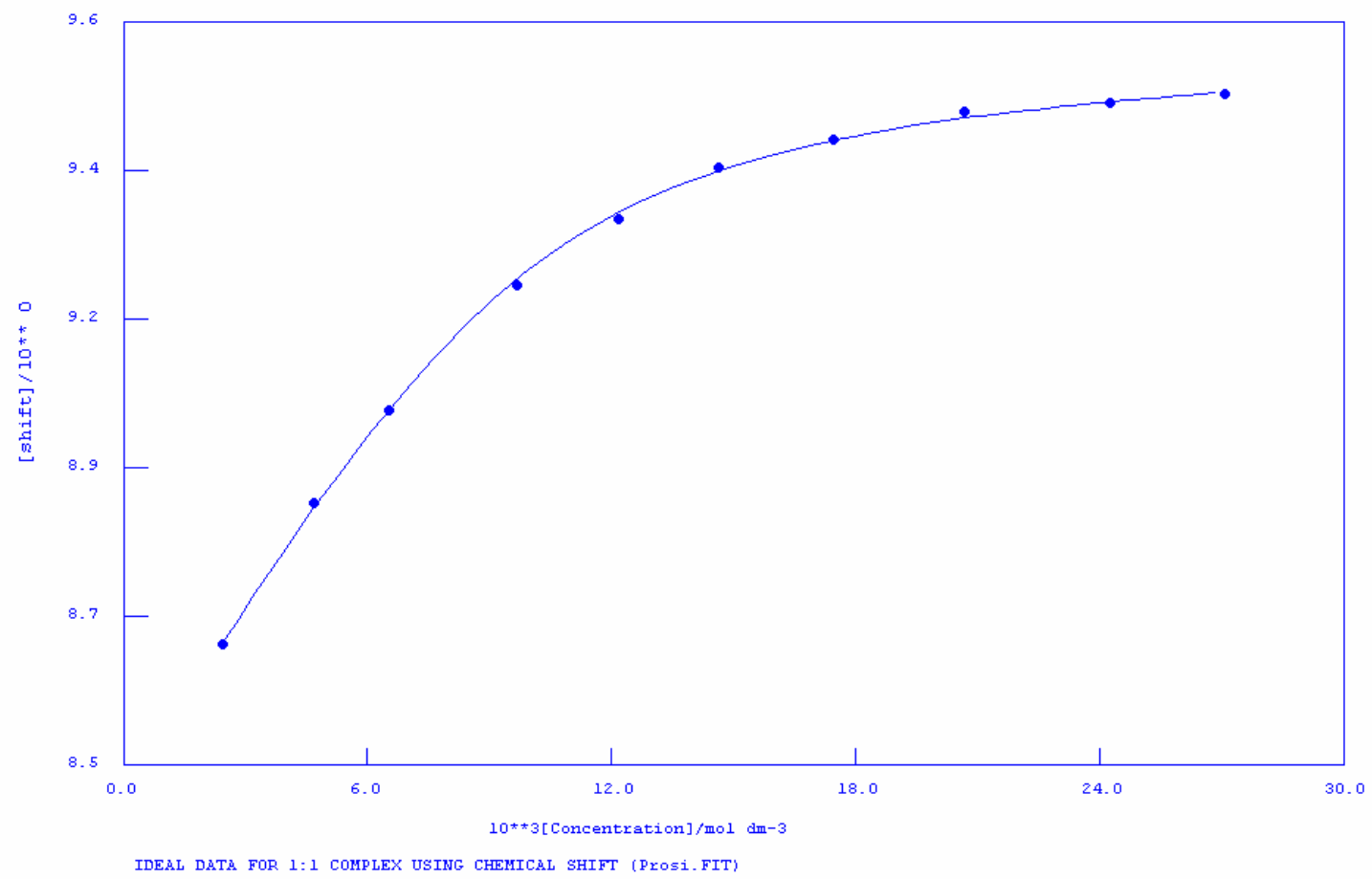

Binding isotherm for $\mathrm{C}(5)$ proton of triazolium unit in receptor 5a with $\mathrm{TBAF}$

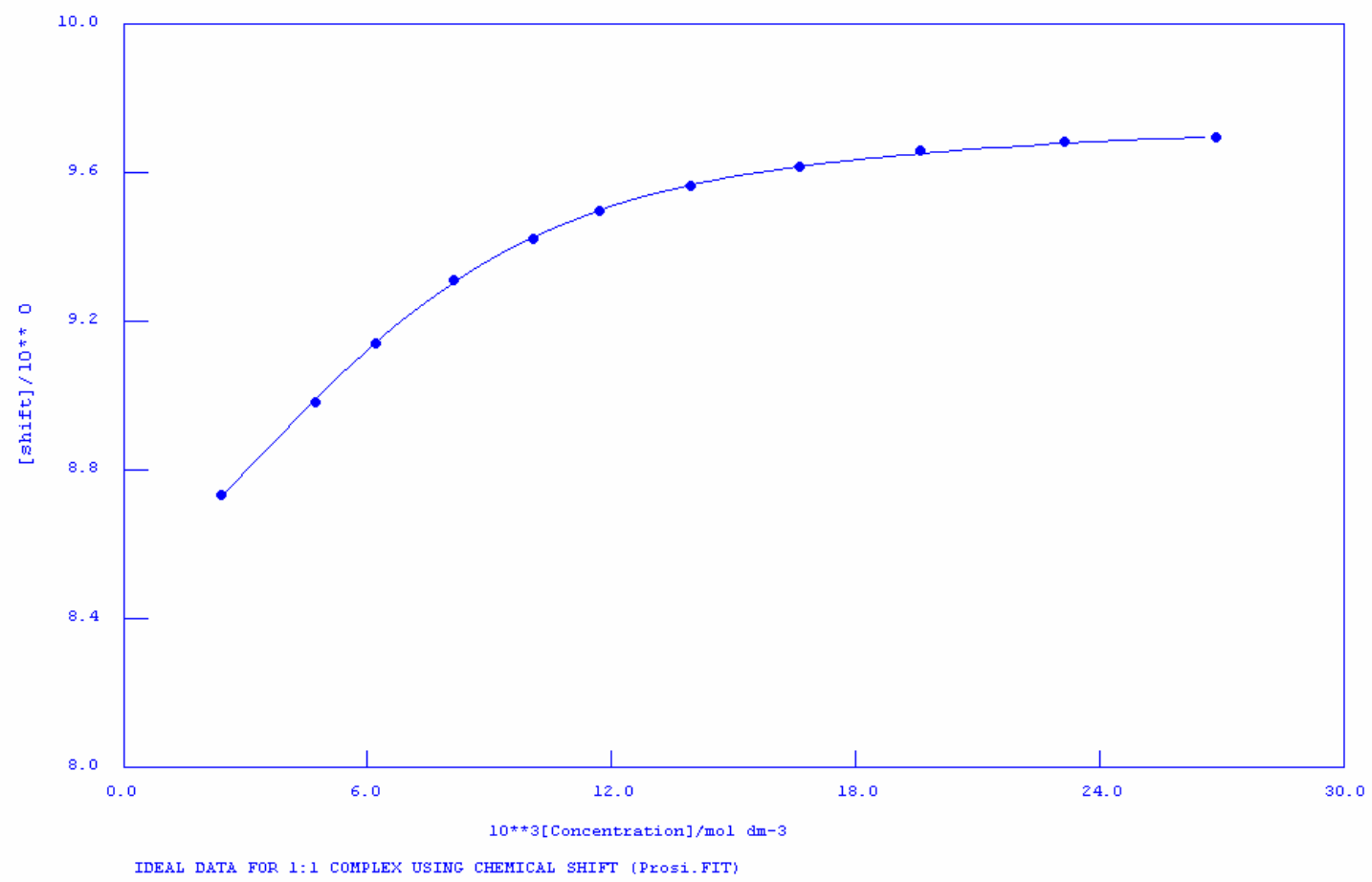

Binding isotherm for $\mathrm{C}(5)$ proton of triazolium unit in receptor $\mathbf{5 b}$ with $\mathrm{TBACl}$ 


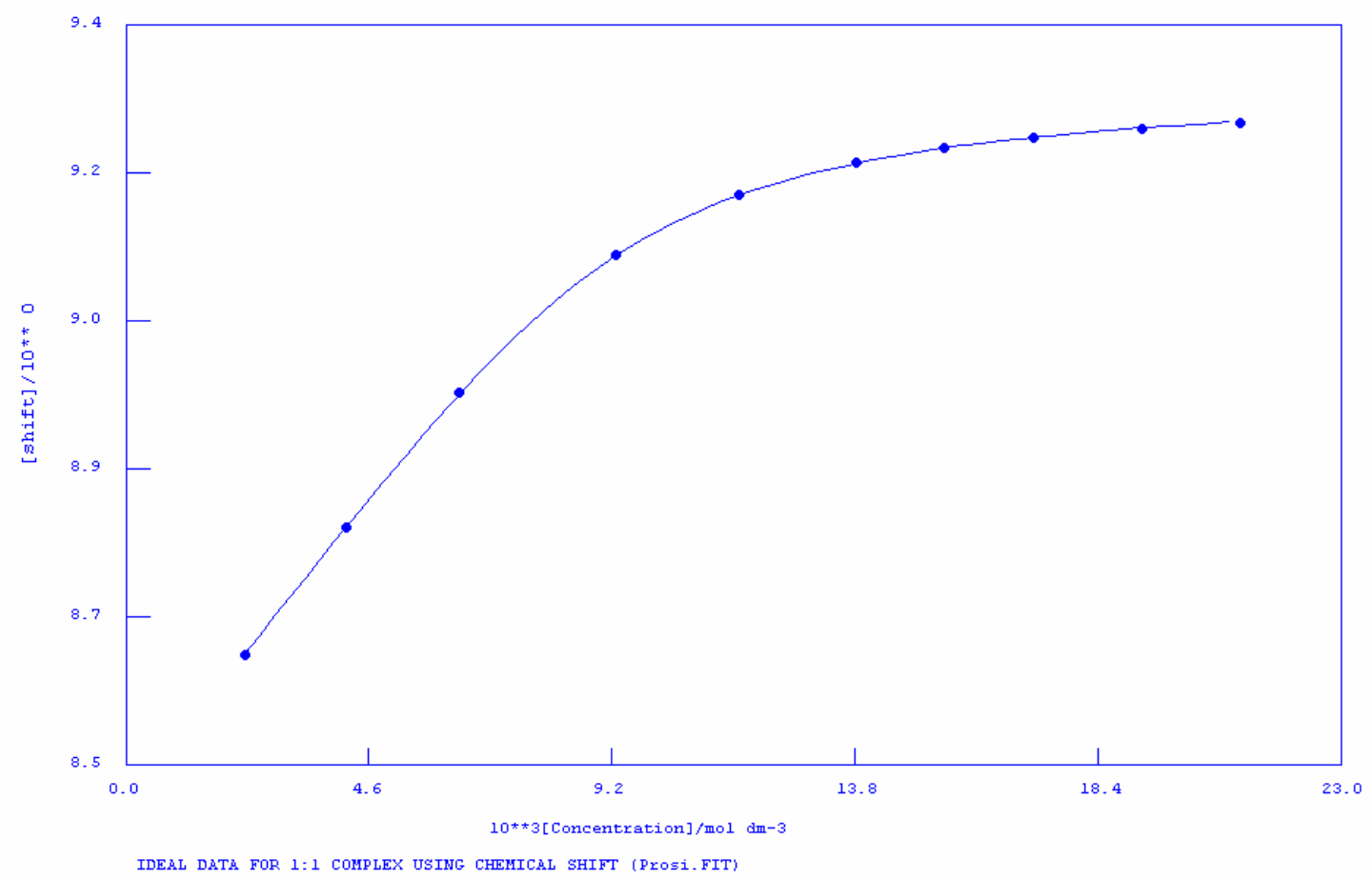

Binding isotherm for $\mathrm{C}(5)$ proton of triazolium unit in receptor $\mathbf{5 b}$ with $\mathrm{TBAH}_{2} \mathrm{PO}_{4}$

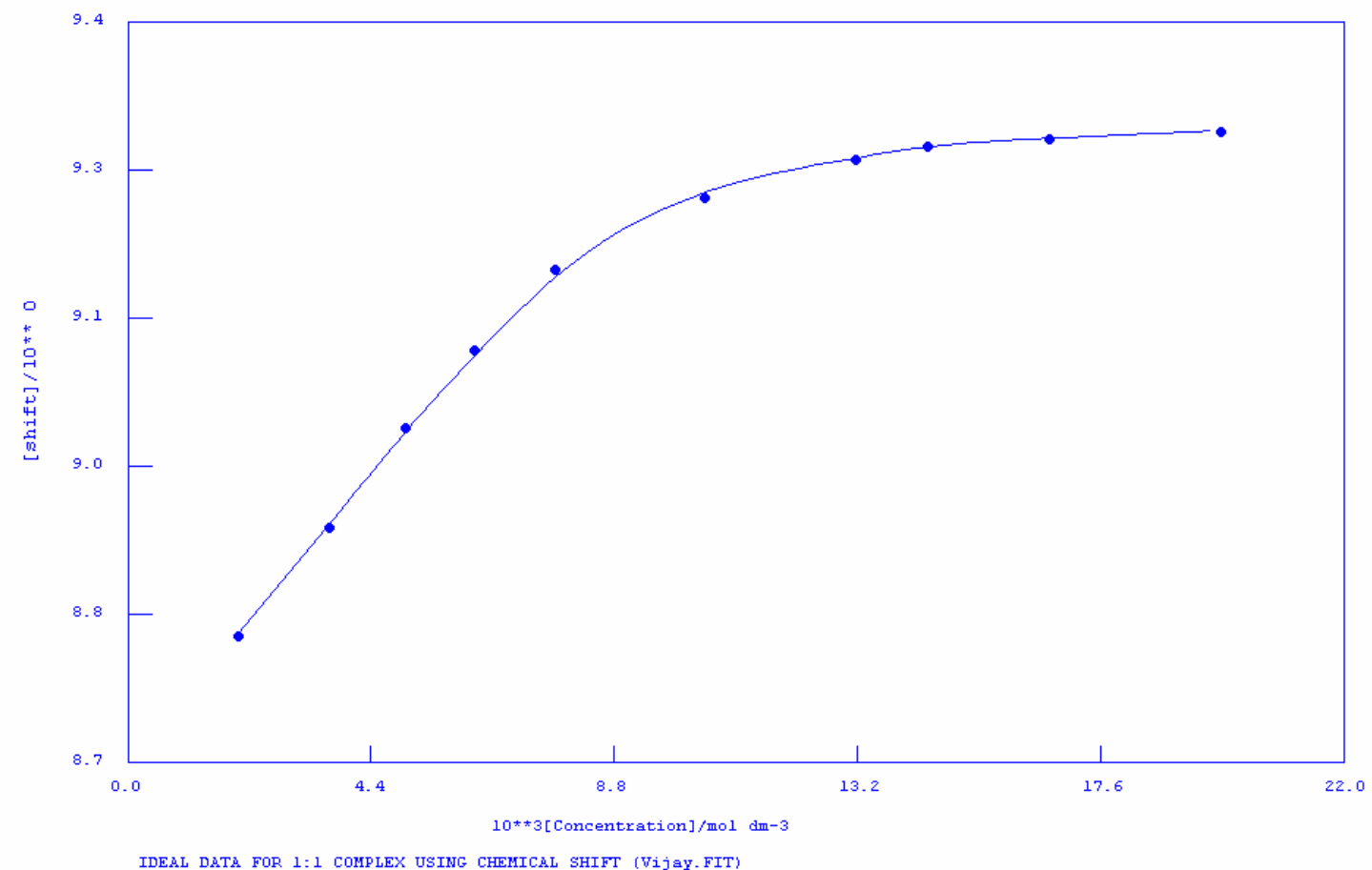

Binding isotherm for $\mathrm{C}(5)$ proton of triazolium unit in receptor 7 with $\mathrm{TBAH}_{2} \mathrm{PO}_{4}$ 


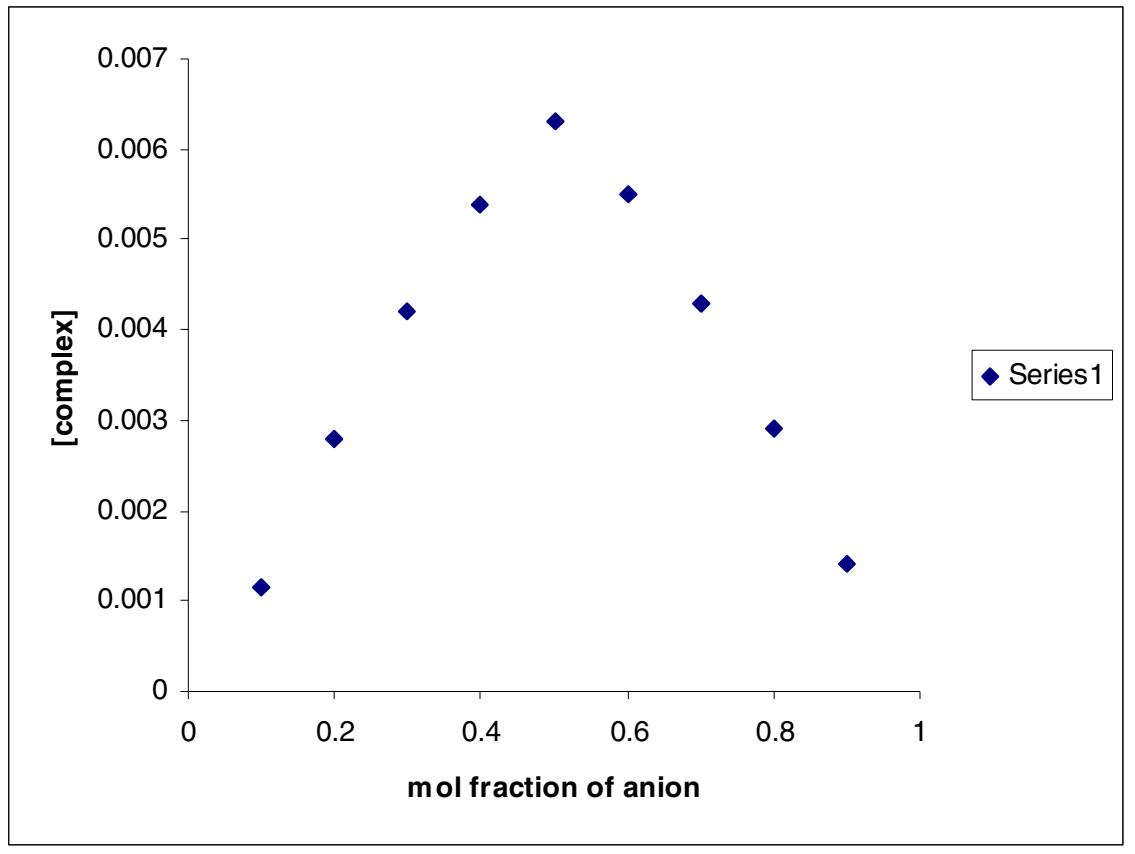

Job plot of compound 5a with TBAF

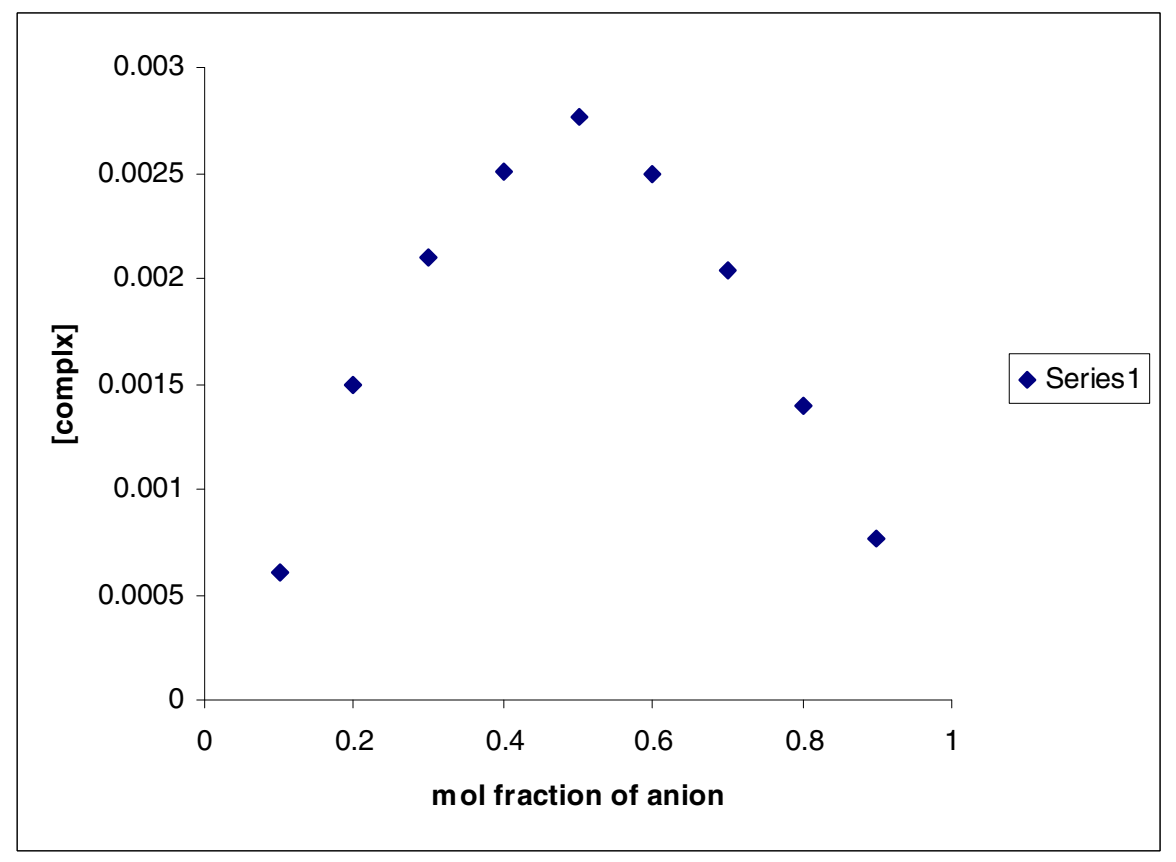

Job plot of compound $\mathbf{5 b}$ with $\mathrm{TBAH}_{2} \mathrm{PO}_{4}$ 


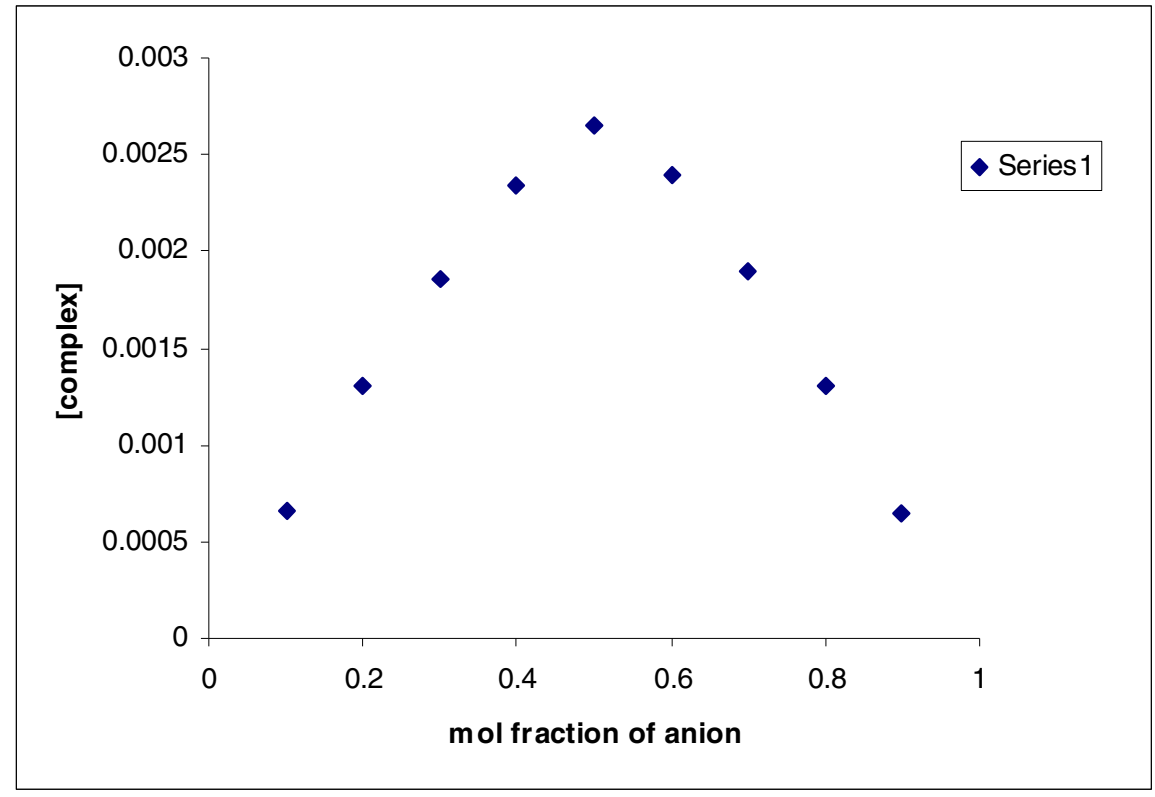

Job plot of compound 7 with $\mathrm{TBAH}_{2} \mathrm{PO}_{4}$ 